\title{
Evaluation of Novel Carbamate Insecticides for Neurotoxicity to Non- Target Species
}

\author{
Ying Jiang
}

Thesis submitted to the faculty of the Virginia Polytechnic Institute and State University in the partial fulfillment for the degree of

Master of Science in Life Science

in

Entomology

Approved by:

Jeffrey R. Bloomquist

Donald E. Mullins

Paul R. Carlier

January 17th, 2011

Blacksburg, VA

Keywords: neurotoxicity, carbamate insecticides, acetylcholinesterase, neurotoxic esterase

(C) 2011, Ying Jiang 


\title{
Evaluation of Novel Carbamate Insecticides for Neurotoxicity to Non-Target Species
}

Ying Jiang

\begin{abstract}
Malaria (vector: Anopheles gambiae) is a major infectious disease that kills about 1 million people each year. For the improvement of its treatment and vector control during the past decades, several issues such as high medicine cost, insecticide resistance, and lack of an effective vaccine have prevented adequate control of malaria. Additionally, the low selectivity of malaria vector insecticides also presents a public health problem. The purpose of developing novel carbamate insecticides in our laboratory is to offer effective and selective insecticide options to achieve the ultimate goal of malaria control.
\end{abstract}

First, 50\% inhibition concentration $\left(\mathrm{IC}_{50}\right)$ data was collected from three mammalian AChEs with eight commercial carbamate insecticides by using the Ellman assay. The $\mathrm{IC}_{50}$ values varied from $57 \mathrm{nM}$ to $7358 \mathrm{nM}$. The AChE sensitivity pattern and level were shown to be similar between the recombinant mouse and ICR male mouse brain cortex homogenate (slope $=0.99, \mathrm{R}^{2}=0.96$ ). Then eight novel carbamate insecticides that are possible malaria vector control agents were selected for further neurotoxicity testing in non-target organisms. For commercial carbamate insecticides, the $\mathrm{IC}_{50}$ varied from $9.1 \mathrm{nM}$ to $2,094 \mathrm{nM}$. For the novel carbamate insecticides, it varied from $58 \mathrm{nM}$ to $388,800 \mathrm{nM}$. Based on $\mathrm{IC}_{50}$ data from previous work on $A$. gambiae, the selectivity index $\left(\mathrm{IC}_{50}\right.$ of non-target species / $\mathrm{IC}_{50}$ A. gambiae) ranged from 0.17 to 5.64 and from 0.47 to 19,587 for commercial and novel carbamate insecticides, respectively.

Subsequently, the AChE protein sequence alignment comparison and cladogram were used to compare the genetic and evolutionary relationship among five different organisms. The alignment 
score ranged from 88 for mouse vs. human to 54 for hen vs. T. californica. The evolutionary relationships among species was obtained from the cladogram. Recombinant mouse vs. recombinant human was shown to have the most similar inhibitor potency profiles (alignment score $=88$, closest taxa position on cladogram, similar AChE sensitivity pattern $\left[R^{2}=0.81\right]$ and level $[P>0.05]$ to the novel carbamates).

Neurotoxic esterase (NTE) assay showed that the novel carbamates did not significantly inhibit NTE, inhibition of which underlies a significant hazard for anticholinesterases, especially organophosphates, in several nontarget vertebrate organisms. The NTE activity in the presence of novel carbamate insecticides ranged from $93 \%$ to $116 \%$ of the control, while in the commercial group, bendiocarb significantly inhibited NTE, leaving only $76.5 \%$ of the initial reactivity at $1 \mathrm{mM}$ inhibitor concentration.

Further in vivo bioassay using Daphnia magna was conducted to compare the aquatic toxicity of commercial and novel carbamates. The data showed that except for PRC331 (3-tertbutylphenylmethylcarbamate), all novel carbamates were of similar potency as bendiocarb $\left(\mathrm{LC}_{50}=\right.$ $611 \mathrm{nM}$ ) for aquatic toxicity, and their $\mathrm{LC}_{50}$ values ranged from $172 \mathrm{nM}$ (PRC331) to $1109 \mathrm{nM}$.

In conclusion, the novel carbamate insecticides would appear to be an improvement over commercial carbamate insecticides because of greater selectivity, negligible NTE inhibition capacity, but in some cases with potent in vivo toxicity to Daphnia magna. However, since the envisioned usage of these compounds is in bednets or as indoor residual sprays (IRS), any environmental exposures to nontarget aquatic organisms are expected to be minimal. 


\section{ACKNOWLEDGEMENTS}

I am very appreciative of the opportunity to study and grow in the Entomology Department of Virginia Polytechnic Institute and State University. My work completed here has received invaluable mentoring of the faculty and help from the staff from this department.

I would like to thank Dr. Jeffrey Bloomquist for the honor to work in his excellent laboratory. His instruction, advice, guidance, and support have helped me to complete my degree.

I am grateful for the advice and direction provided by my former committee members, Dr Marion Ehrich, Dr. Dennis Blodgett, Dr. Bradley Klein and new committee members, Dr. Paul Carlier and Dr. Donald Mullins.

I need to thank Dr. Marion Ehrich and member of her laboratory, Kristel Fuhrman, in the Department of Biomedical Sciences \& Pathobiology, Virginia Tech, for providing the hen's brain sample and assistance in NTE assay, without whom this work couldn't be completed. Explicitly, I would like to thank Ms Kristel Fuhrman for her advice and the joy of working with her.

I would like to thank Dr. Paul Carlier and his present and former lab members at the Chemistry Department in Virginia Tech. Because of their help and hard work, I could finish my project with sufficient and high quality test compounds.

I would like to thank Dr. Fredrik Ekström and his lab members for providing the source of mouse and human AChE enzymes from the Swedish Defense Research Agency.

I would like to extend one special appreciation to Dr. Dawn Wong for her invaluable advice, lessons, and happy lab hours. 


\section{Table of Contents}

Section Page

Abstract. ..ii

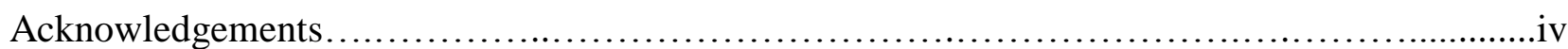

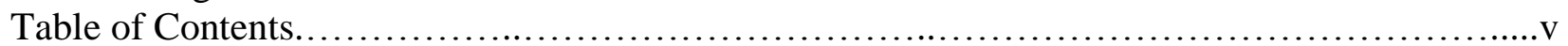

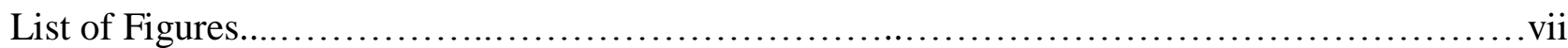

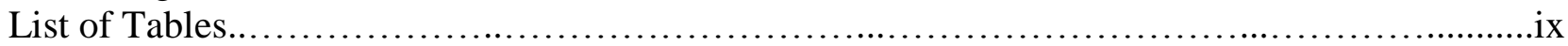

\section{Chapter 1: Introduction and Review of Literatures}

1.1. General Introduction of Malaria and Current Malaria Control Methods .........................1

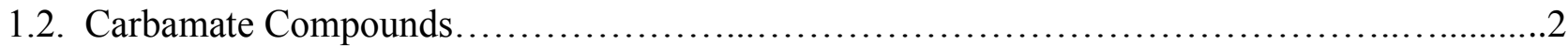

1.2.1. Structure of Carbamates..........................................................

1.2.2. General Metabolism of Carbamates ................................................. 4

1.2.2.1. Absorption of Carbamates ............................................4

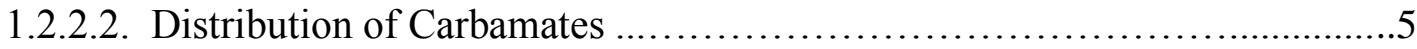

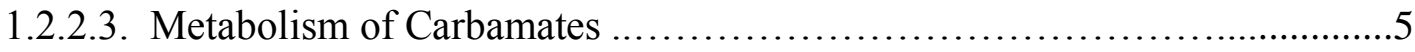

1.2.2.3.1 Phase I Reactions.............................................

1.2.2.3.2. Phase II Reactions........................................... 10

1.2.3. Pharmacodynamics and Pharmacokinetics of Carbamates Insecticides.................11

1.2.3.1. The Acetylcholine System........................................11

1.2.3.1.1. Introduction of the Acetylcholine System......................11

1.2.3.1.2. Mode of Action and Pharmacokinetics of Carbamate and Organophosphate Compounds on Acetylcholine System..........12

1.2.3.1.3. Structure-Activity Relationships of Carbamate Insecticides on Acetylcholinesterase.....................................15

1.2.3.2. Neurotoxic Esterase and OPIDN ................................... 17

1.2.3.2.1. Introduction of Neurotoxic Esterase and OPIDN................17

1.2.3.2.2. Mode of Action and Pharmacokinetics of Carbamate and Organophosphate Compounds on NTE.........................19

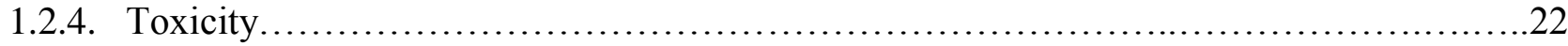

1.2.4.1 Toxicity of Carbamate Compounds in Human...................................22

1.2.4.2. Methods to Test Reactivity of Carbamate Compounds.............................23

1.2.4.2.1. Ellman Assay for Cholinesterase Reactivity.............................23

1.2.4.2.2. Neurotoxic Esterase Assay..........................................24

Chapter 2: Experimental Design and Methods...............................................25

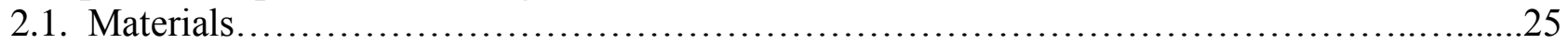

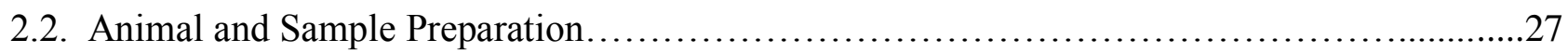

2.2.1. Recombinant Human and Mouse AChE..............................................27

2.2.2. Hen Brain Homogenate........................................................27

2.2.3. Electrophorus electricus AChE..............................................27

2.2.4. Torpedo californica Homogenate...........................................28

2.2.5. Daphnia magna Homogenate.................................................28

2.2.6. Anopheles gambiae Homogenate............................................29

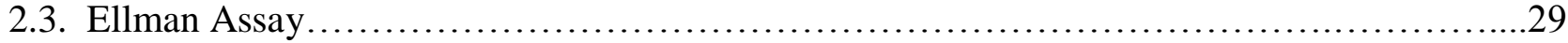


2.3.1. Dilution Methods for Ellman Assay ..............................................30

2.3.1.1. Method 1. A Series Dilution with a Constant DMSO (DWCD) Concentrations Procedures for AChE Assays............................30

2.3.1.2. Method 2. A Series Dilution with Various DMSO (DW/OCD

Concentrations Procedures for AChE Assays..................................31

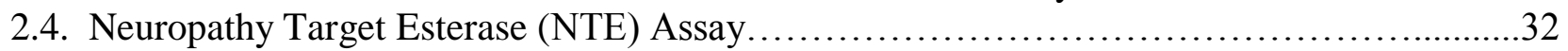

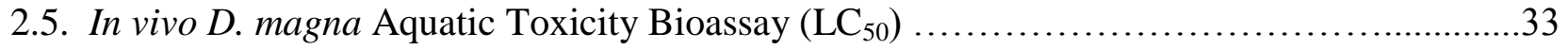

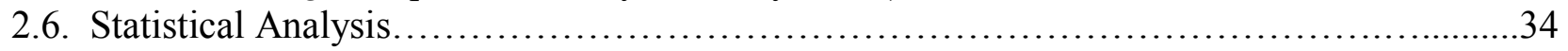

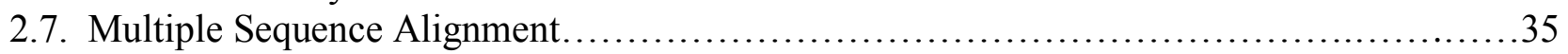

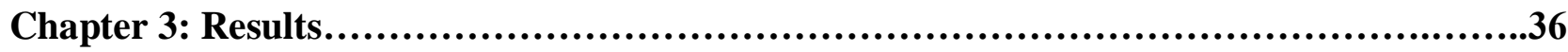

3.1. Assay Validation for Comparison with Previous Results.....................................36

3.2. Solvent Effect on Ellman Assay ......................................................... 40

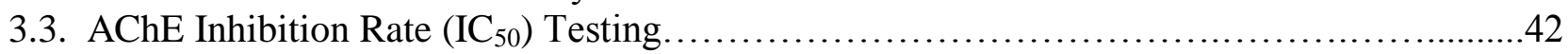

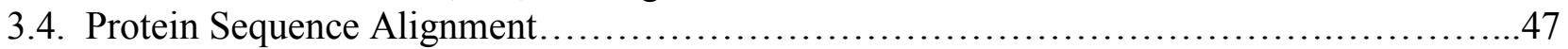

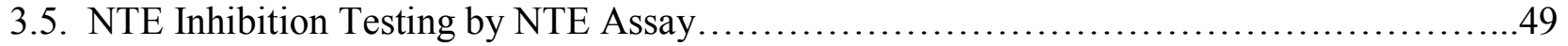

3.6. In vivo D. magna Aquatic Toxicity Bioassay...............................................

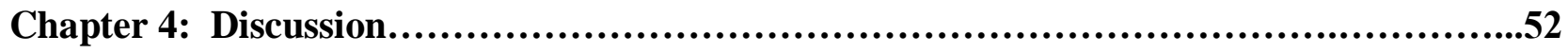

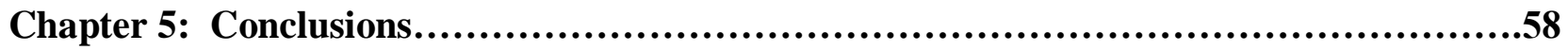

Chapter 6: References...................................................................61 


\section{List of Figures}

Figure 1-1. Structure of carbamate compounds........................................

Figure 1-2. Ring oxidation of 2-isopropoxyphenyl methylcarbamate (Propoxur)................7

Figure 1-3. Naphthalen-1-yl methylcarbamate is catalyzed by MFOs and metabolized into the epoxidation intermediate product, the naphtho[2,3-b]oxiren-3-yl methylcarbamate .7

Figure 1-4. MFOs-catalyzed mexacarbate $N$-dealkylation of side chain.......................8

Figure 1-5. MFOs-catalyzed propoxur $O$-dealkylation of the side chain, forming the metabolite: 2 --hydroxyphenyl methylcarbamate.............................8

Figure 1-6. MFOs catalyzed mexacarbate hydroxylation on alkyl side chain and oxidative hydrolysis.

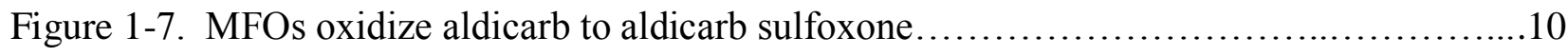

Figure 1-8. Acetylcholine hydrolysis by acetylcholinesterase ............................. 12

Figure 1-9. Diagram demonstrating the reaction between serine hydrolase (acetylcholinesterase) and a carbamate...

Figure 1-10. Structure of Mipafox and Diisopropylfluorophosphate (DFP)

Figure 1-11. Diagram demonstrating the reaction between serine hydrolase (neurotoxic esterase) and different organophosphate compounds..............................22

Figure 1-12. Ellman assay reaction procedures.......................................24

Figure 2-1. The procedure of dilution without constant DMSO concentration method for Ellman assay.

Figure 2-2. The procedure of dilution with constant DMSO concentration method for Ellman assay.

Figure 3-1. Ellman Assay results using dilution without constant DMSO concentration

Figure 3-2. Comparison of regression correlation of $\mathrm{IC}_{50}$ (commercial carbamates) between ICR mouse brain homogenate and recombinant mouse acetylcholinesterase.

Figure 3-3. Examples of DW/OCD results of the novel carbamate insecticides. 
Figure 3-4. Cladogram comparing the relationships between acetylcholinesterase from five animals............................................................. 49 


\section{List of Tables}

Table 1-1. Structure of neuropathic and non-neuropathic organophosphate compounds

Table 2-1. Structure name and chemical name of novel carbamate insecticides that were tested in this study

Table 3-1. IC $_{50}$ obtained from 9 commercial carbamate insecticides tested on untreated male ICR mouse brain cortex homogenate, recombinant mouse and recombinant human acetylcholinesterase. Dilution without constant DMSO concentration dilution method was used for Ellman assay dilution.

Table 3-2. $\mathrm{IC}_{50}$ and selectivity index data obtained from 6 non-target species acetylcholinesterases using dilution with constant DMSO concentration for Ellman assay dilution....

Table 3-3. Comparison of the $\mathrm{R}^{2}$-value of the regression line between acetylcholinesterases of different animal species

Table 3-4. Summary of the multiple sequence alignment using 5 different animal species' acetylcholinesterases' protein sequence...

Table 3-5. Comparison of neurotoxic esterase assay results by using hen brain homogenate......50

Table 3-6. In vitro toxicity aquatic bioassay results by using $D$. magna .......................51 


\section{Chapter 1: Introduction and Review of Literatures}

\subsection{General Introduction of Malaria and Current Malaria Control Methods}

Malaria, which is a vector-borne disease, remains an urgent global health issue and once again has the attention of the international health community (Na-Bangchang and Congpuong 2007; O'Meara et al. 2010; Ringwald 2007). According to data from the United Nations Children's Fund (UNICEF) in 2008, malaria is still a widespread disease, particularly in many countries of Africa and Asia, which infects approximately 100-300 million people and kills 1-3 million people every year (Anonymous 2008). In addition, in Africa, more than 2500 children under 5 years old are killed every day because of malaria (Ringwald 2001). So there is an urgent need for malaria control.

Current malaria control methods include epidemiological prevention and chemotherapy. Although searching for new medicines for malaria chemotherapy for many years, the clinics so far are still heavily dependant on limited compounds. These compounds belong to four categories, including the 4- or 8-aminoquinoline group, the antifolate group, the artemisinin group and the hydroxynapthoquinone/atovaquone group (Croft et al. 2002; Popov et al. 2003; Schlitzer 2008). Because of limited chemical compound diversity (Jamshidzadeh et al. 2007), more resistant malarial pathogen infection cases and untreatable cases have been reported (Dondorp et al. 2009; NaBangchang and Karbwang 2009; Schlagenhauf and Petersen 2009). In addition, lack of an efficient malaria pathogen vaccine makes disease control even more difficult (Tetteh and Polley 2007; WHO 2005). As a vector-borne disease, the transmission of malaria depends highly on its insect vector, which are mosquitoes of the genus Anopheles, including Anopheles gambiae (Beier et al. 1990). In 2007, WHO reconfirmed the importance of malaria vector control in malaria reduction programs (Van den Berg 2009). In Africa, it has been reported that after appropriate insecticide usage, there is 
a significant reduction in the parasite prevalence and malaria diagnosis (Bhattarai et al. 2007). On top of that, compared to antimalarial medicines, the relatively high cost-efficiency of insecticides makes them more affordable for countries suffering from malaria (Conteh et al. 2004). In conclusion, the growing emphasis on malarial vector control impels the attention on insecticide research.

Carbamate insecticides belong to an insecticide category that targets acetylcholinesterase (AChE). Carbamates have been widely applied onto bednets and as indoor sprays in malarial control in recent years and achieved some positive results (Akogbéto et al. 2010; Djènontin et al. 2009; Djènontin et al. 2010), but the increasing number of reports finding carbamate- and organophosphate-resistant A. gambiae stains requires the discovery of alternative anticholinesterases (Boon et al. 2008; Corbel et al. 2003; Mostafa and Allam 2001; N'Guessan et al. 2003). In the following pages, brief introduction will be given on the structure, pharmacodynamics, pharmacokinetics, and toxicity of carbamate and organophosphate insecticides. Furthermore, promising data and structures of newly developed novel carbamate insecticides from Dr. Jeffrey Bloomquist's and Dr. Paul Carlier's collaboration will be discussed.

\subsection{Carbamate Compounds}

A carbamate compound active on acetylcholinesterase was first discovered in the extract of Physostigma venenosum (calabar bean) (Proudfoot 2006). The first described carbamate anticholinesterase was called physostigmine (Figure 1b), which is an ester form of methylcarbamate. As an anticholinesterase, physostigmine was used initially as one treatment option for myasthenia gravis (Flacke 1973). In addition, the symptoms of glaucoma, Alzheimer's disease, and delayed gastric emptying can also be relieved through the same mechanism (Rathmann and Conner 2007, 
Loewenstein et al. 1993, Ulvestad and Gerner 1984). In this thesis, I will focus on the discussion of carbamates used for insecticidal purposes.

\subsubsection{Structure of Carbamates}

Generally speaking, carbamate compounds are colorless, odorless, crystalline powders at room temperature (Baron 1991), and are derived from their parent compound, carbamic acid, whose generic structure is $\mathrm{NH}_{2} \mathrm{COOH}$. The structures of example carbamate compounds are shown in Figure 1-1. The functional group in carbamate compounds is also called urethane and defined as $\mathrm{R}_{1} \mathrm{R}_{2} \mathrm{NCOOR}_{3}$, where $\mathrm{R}_{1}$ and $\mathrm{R}_{2}$ represent chemical groups including hydrogen and short-chain alkyls, such as methyl and ethyl groups, while $\mathrm{R}_{3}$ is usually oxime or cyclic unsaturated hydrocarbon such as phenol or naphthol. The substituent at $R_{1}$ and $R_{2}$ positions will change the binding of carbamate compounds with AChE greatly, which is the basis for selectivity and structure-activity relationships of carbamate insecticides.<smiles>[R]OC(=O)N([R])[R]</smiles>

a.<smiles>CNC(=O)Oc1ccc2c(c1)[C@]1(C)CCN(C)[C@@]1(C)N2C</smiles>

(3aS,8aR)-1,3a,8-trimethyl $-1,2,3,3 a, 8,8 a-h e x a h y d r o p y r r o l o$ [2,3-b]indol-5-yl methylcarbamate<smiles>CNC(=O)Oc1cccc2c1OC(C)(C)O2</smiles>

2,2-dimethylbenzo[d] $[1,3]$ dioxol-4-yl methylcarbamate

c.

Figure 1-1. Structure of carbamate compounds. a. General structure of carbamate compounds. $R_{1}$ and $R_{2}$ represent chemical groups including hydrogen and short-chain alkyl. $\mathrm{R}_{3}$ is usually a cyclic unsaturated hydrocarbon. $\mathrm{b}$. Structure 
of physostigmine ((3aS,8aR)-1,3a,8-trimethyl-1,2,3,3a,8,8a-hexahydropyrrolo[2,3-b]indol-5-yl methylcarbamate). c. Structure of bendiocarb (2,2-dimethylbenzo[d][1,3]dioxol-4-yl methylcarbamate).

\subsubsection{General Metabolism of Carbamates}

The pharmacokinetics of carbamate compound in the animal body includes 4 steps, which are absorption, distribution, metabolism and excretion (Timchalk 2006).

\subsubsection{Absorption of Carbamates}

Three pathways for insecticide absorption have been demonstrated, including oral exposure (Bardin et al. 1994), dermal exposure (Johansson 1992), and respiratory exposure (Baban et al. 1998). Oral exposure is thought to be the most important route for carbamate absorption. Exposure usually happens during food intake because of carbamate insecticide residuals on food (Barnat et al. 2010; Boon et al. 2008). Other examples can occur, such as intentional ingestion for suicide purpose (Ameno et al. 2001; Barnat et al. 2010). Likewise, dermal exposure is also an important exposure route, which is more prevalent in certain groups of people. It has been reported that workers involved in agricultural product processing, such as tobacco (Lonsway et al. 1997), have much higher carbamate compound deposition in their body than the average population (Calli and Marinovich 1987). This deposition is thought to mainly come from the dermal pathway. In addition, during carbamate insecticide production and preparation, such as mixing and loading, workers can also be exposed through dermal contact (Calli and Marinovich 1987). Although not considered as a major route, carbamate compound exposure through inhalation is still considered a possible route because some carbamate compounds are volatile (Hall and Harris 1979). Additionally, the airway is also an important exposure route during agriculture production, where workers inhale carbamate spray drift or contaminated dust during insecticide application (Hall and Harris 1979). Large doses 
of carbamate through inhalation could cause pulmonary edema and respiratory stress, which is thought to be a major reason of death by carbamate intoxication (Salisbury et al. 1974).

\subsubsection{Distribution of Carbamates}

Upon absorption, carbamate compounds distribute throughout the body rapidly. Ahdaha et al. (1981) found that the half-life is from 8 to 17 minutes for carbamate penetration through organs. Pharmacokinetic research further suggested that fast distribution of carbamate compounds fits a onecompartmental model (Timchalk 2006). For example, one large oral dose administrated in the human body, of carbamate (chlorphenesin) reached serum concentrations, with mean lag times and half-lives for absorption of a one compartmental model (Forist and Judy 1971). A study using pyridinol carbamate obtained a similar result (Sassard et al. 1979).

\subsubsection{Metabolism of Carbamates}

The purpose of metabolism in animals is to make xenobiotics more polar (Parke and Williams 1969; Timchalk 2006; Williams 1959). The metabolites of the xenobiotics could then be excreted from the body after metabolism. Since they are hydrophobic, carbamate compounds require efficient metabolism in the body to detoxicate them by making their metabolites hydrophilic (Ioannides 2002; Jakoby and Ziegler 1990; Parvez et al. 2001). Like other xenobiotics, the metabolism of carbamate compounds in animals involves both phase I and phase II reaction (Tang et al. 2006).

\subsection{Phase I Reactions}


The major function of Phase I reactions is to form proper functional groups for Phase II derivitization (Tang et al. 2006). Generally speaking, Phase I reactions help to detoxicate xenobiotics and serve as a protective mechanism for animals (Hodgson and Goldstein 2001; Parkinson 2001). However, in some situations, this oxidation can increase the toxicity of xenobiotics, which facilitate the intoxication process. For example, both in vivo and in vitro, the metabolites of aldicarb, such as aldicarb sulfone and aldicarb sulfoxide, were more potent AChE inhibitors than aldicarb (Pelekis and Krishnan 1997).

For carbamate compounds, Phase I reactions are conducted by the mixed function oxidase system (MFO), which mainly catalyze oxidation (including epoxidation, dealkylation, sulfoxidation and hydroxylation) and hydrolysis (Tang et al. 2006). Liver is the major site responsible for these reactions in animals (Pekas and Paulson 1970), and the highest amount of MFO is in cellular microsomes (Gillette et al. 1969). During MFO reactions, NADPH serves as a cofactor and cytochrome P450 is the major electron transport enzyme system (Gillette et al. 1969; Brodie et al. 1958).

Oxidation is the most important metabolic process for carbamate compounds. Although there are many potential oxidation sites for carbamates, these sites could be categorized into two groups, which are either on ring or on side chain. Ring hydroxylation was first found in carbaryl (Dorough et al. 1963). In that paper, Dorough et al. incubated carbaryl with rat liver homogenate and found two ring hydroxylation products, which are 4-hydroxy- and 5-hydroxycarbaryl. Later, the same metabolism processes were also found for other carbamate insecticides, such as carbofuran (Dorough 1968; Metcalf et al. 1968). An example of ring hydroxylation is shown below (Figure 12): 


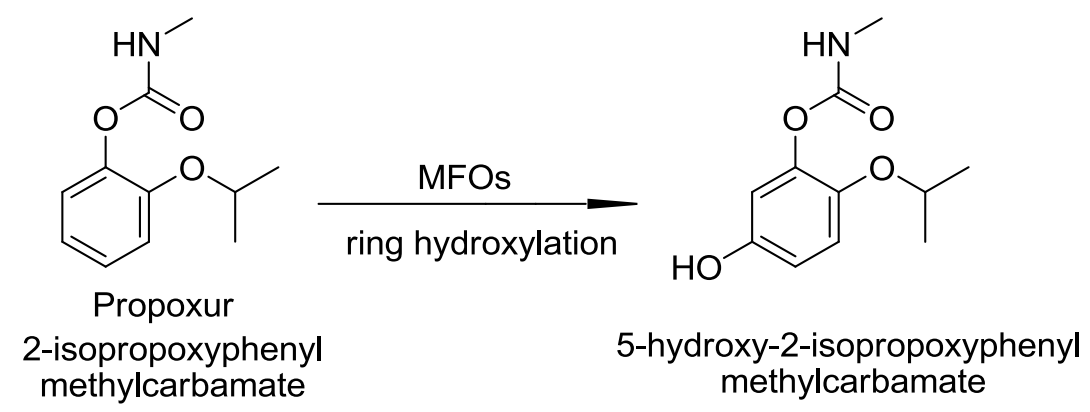

Figure 1-2. Ring oxidation on 2-isopropoxyphenyl methylcarbamate (Propoxur). After MFOs' catalysis, propoxur is converted to 5-hydroxy-2-isopropoxyphenyl methylcarbamate.

Sometimes, this oxidation process may require an intermediate step called epoxidation (Hodgson and Goldstein 2001). For example, carbaryl ring hydroxylation requires an epoxide intermediate derivative (Figure 1-3).

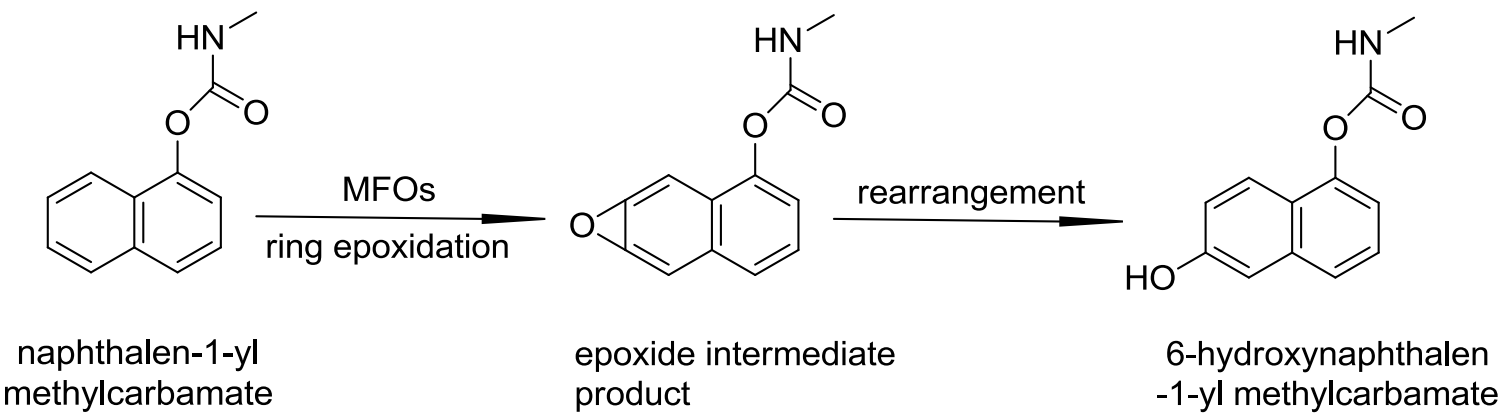

Figure 1-3. Naphthalen-1-yl methylcarbamate is catalyzed by MFOs and metabolized into the epoxidation intermediate product, the naphtho[2,3-b]oxiren-3-yl methylcarbamate. MFOs further catalyze the transfer of the naphtho[2,3b]oxiren-3-yl methylcarbamate to 6-hydroxynaphthalen-1-yl methylcarbamate.

Side chain oxidation can occur in many places, which may include $N$ - and $O$-dealkylation, resulting from hydroxylation on the alkyl side chain, and hydrolysis. For example, N-dealkylation could proceed at two different sites in mexacarbate (Zectran or N-Methyl 4-dimethyamino-3,5-xylyl carbamate) (Figure 1-4). 

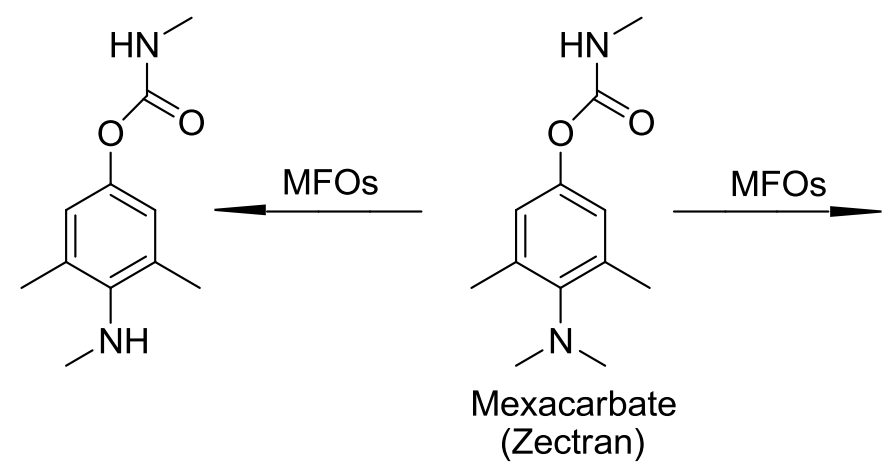<smiles>Cc1cc(OC(N)=O)cc(C)c1N(C)C</smiles>

(Zectran)

\section{3,5-dimethyl- 4-(methylamino)phenyl methylcarbamate}

Figure 1-4. MFOs-catalyzed mexacarbate $N$-dealkylation of side chain. MFOs catalyzed mexacarbate (4(dimethylamino)-3,5-dimethylphenyl methylcarbamate) $N$-dealkylation on side chain, the metabolites were: 3,5dimethyl-4-(methylamino)phenyl methylcarbamate (left), and 4-(dimethylamino)-3,5-dimethylphenyl carbamate (right).

An example of $O$-dealkylation can be found in propoxur (Figure 1-5). Other side chain oxidation includes hydroxylation on alkyl side chain and oxidative hydrolysis. Examples of these reactions are shown below in Figure 1-6.

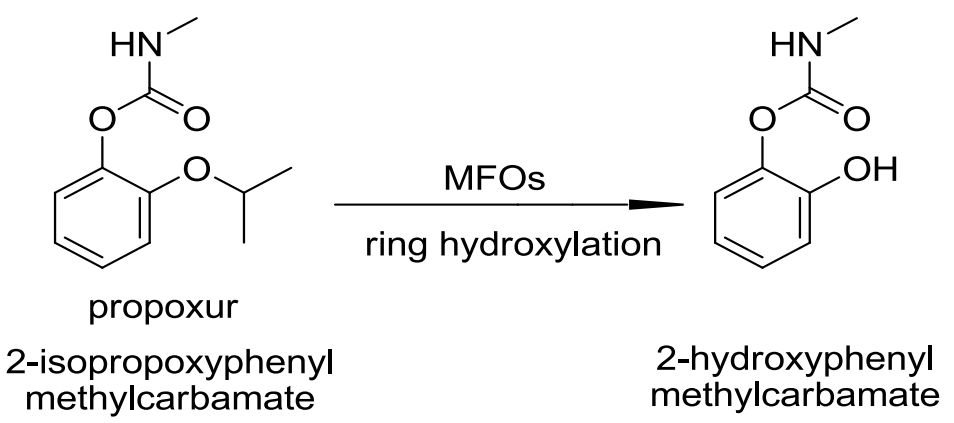

Figure 1-5. MFOs-catalyzed propoxur $O$-dealkylation of the side chain, forming the metabolite: 2--hydroxyphenyl methylcarbamate. 

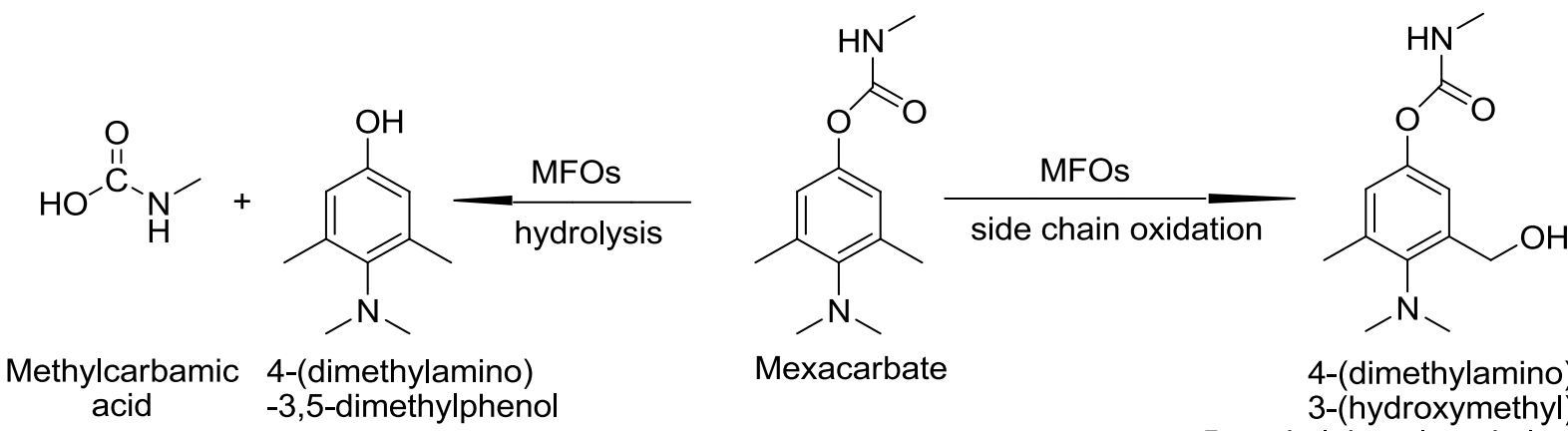

4-(dimethylamino)3-(hydroxymethyl)5-methylphenyl methylcarbamate

Figure 1-6. MFOs-catalyzed mexacarbate (4-(dimethylamino)-3,5-dimethylphenyl methylcarbamate) hydroxylation on alkyl side chain and oxidative hydrolysis. The products of hydrolysis are 4-(dimethylamino)-3,5-dimethylphenol and methylcarbamic acid. The products of side chain oxidation are 4-(dimethylamino)-3-(hydroxymethyl)-5-methylphenyl methylcarbamate.

As mentioned above, sulfoxidation is a unique oxidation process that can sometimes activate rather than detoxicate aldicarb in Phase I reactions. This oxidation happens only in a very specific group of carbamate compounds called thiocarbamates (Matsumura 1985; Tang et al. 2006). In the thiocarbamate family, all of its members have a thioether substituent in their chemical structures. Although S-dealkylation was also reported during Phase I reactions (Hodgson and Goldstein 2001), this reaction is believed to be rare in thiocarbamates (Tang et al. 2006). Aldicarb has been studied extensively (Kuhr and Dorough 1976; Pelekis and Krishnan 1997). Aldicarb oxidatized derivatives, such as aldicarb sulfoxide and aldicarb sulfone, become more potent AChE inhibitors (Oonnithan and Casida 1968). Foran et al. (1985) reported that the aldicarb sulfoxidation increased the toxicity of aldicarb by using in vivo Daphnia magna bioassay. When tested with on adult $D$. magna, the 48 hour $\mathrm{IC}_{50}$ of aldicarb, aldicarb sulfoxide and aldicarb sulfone were 51 (45-59) ug/L, 43 (39-46) ug/L and 369 (320-430) ug/L, respectively. Similarly, the $48 \mathrm{~h} \mathrm{LC}_{50}$ reading of aldicarb and aldicarb sulfoxide and aldicarb sulfone were 209 (173-265) ug/L, 103 (36-142) ug/L and 1124 (993-1320) ug/L, respectively. Some other sulfoxidation-activation examples are benfuracarb, carbosulfan, 
mecarbam, and thiodicarb (Ecobichon 2001). However, this sulfoxidation activation so far has not been shown to apply to all thiocarbamates. This reaction is shown below (Figure 1-7).

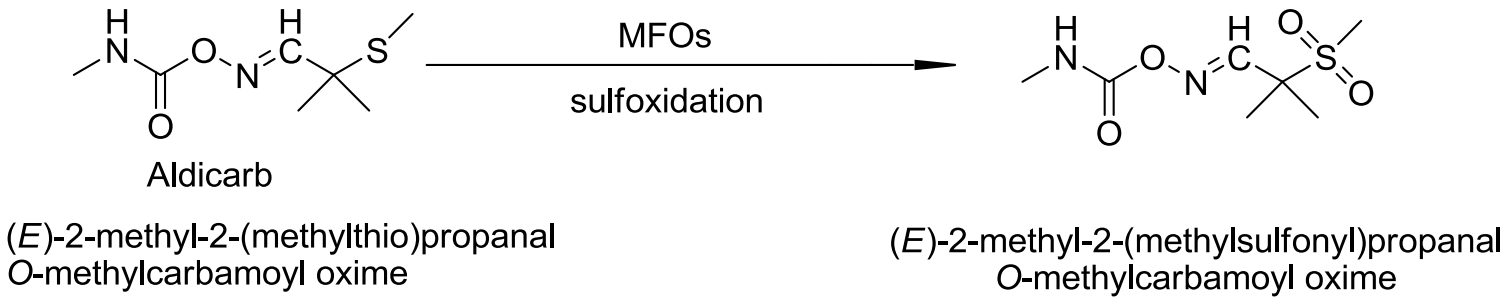

Figure 1-7. MFOs oxidize aldicarb [(E)-2-methyl-2-(methylthio) propanal O-methylcarbamoyl oxime] to aldicarb sulfoxone [(E)-2-methyl-2-(methylsulfonyl)propanal O-methylcarbamoyl oxime].

\subsection{Phase II Reactions}

After Phase I reactions, Phase II reactions will make further modification of carbamate compounds (Chen and Dorough 1979; Dorough 1968; Hodgson and Rose 2004; Kuhr and Dorough 1976; Tang et al. 2006). Generally speaking, Phase II reactions are biosynthetic, and will add hydrophilic substituents to xenobiotics, which facilitates excretion (Dorough 1979; Kuhr and Dorough 1976; Tang et al. 2006). There are four kinds of Phase II enzymes, which are glutathione transferases (GST), glucuronosyl transferases, sulfotransferases (SULT) and acetyltransferases (Parkinson 2001; Sies and Packer 2005; WHO 1986). Glutathione (GSH) is the cofactor that GST uses to conjugate with xenobiotics (Kuhr and Dorough 1976). In vertebrates, glucosidation is conducted by uridine diphosphate glucuronosyltransferase, one member of the glucuronosyl transferases family, which uses glucuronic acid from uridine diphosphate glucuronic acid (UDPGA) (Dorough 1979; Tang et al. 2006). SULT and acetyltransferases catalyze sulfation and acetylation, respectively (Parkinson 2001). Glutathione sulfate, mercapturic acid or glucuronide are connected to the metabolites of carbamate compounds from Phase I reaction. All these conjugated xenobiotics 
metabolites become more hydrophilic than their parent compounds, which facilitate their final excretion either through the kidney or feces (Dorough 1979; Parkinson 2001; Tang et al. 2006).

\subsubsection{Pharmacodynamics \& Pharmacokinetics of Carbamates Insecticides}

\subsubsection{The Acetylcholine System}

\subsection{Introduction of The Acetylcholine System}

Acetylcholine (ACh) is a neurotransmitter present at both neuromuscular junction and nerve cholinergic synapses in mammals, but only in the central nervous system in insects (Callec 1985; Nation 2002). The serine hydrolase family includes acetylcholinesterase (AChE), carboxylesterases, butyrylcholinesterase (BChE), neuropathy target esterase (NTE) and other esterases (Marrs and Ballantyne 2004; Massoulié et al. 1993). The main physiological function of AChE is to quickly terminate the transmitter function of $\mathrm{ACh}$ and prevent toxic effects from over-accumulation of $\mathrm{ACh}$ at synaptic cleft (Fukuto 1990). After reviewing the gene sequence, secondary structure, and 3-D structure of AChE (Sussman et al. 1991), it is clear that although the amino acid sequence is not conserved among species (Wiesner et al. 2007), the overall structure of AChE is highly conserved and consists of three functional regions, which are the catalytic anionic site (CAS), peripheral anionic site (PAS) and a connecting gorge (Bourne et al. 1995; 1999). X-ray crystallography shows that the gorge is a long and deep structure that is lined by 14 conserved aromatic residues (Bourne et al. 1995; Sussman et al. 1991). The CAS is located at the bottom of the gorge, which has the catalytic triad, Ser203, His447 and Glu334 (Bourne et al. 1995; Sussman et al. 1991). There are also four other subsites near the CAS, which are the esteratic site (Pavlic 1975; Wilson 1951), oxyanion hole (Ordentlich et al. 1998), anionic subsite (Bucht et al. 1994) and the acyl pocket (Taylor and Radic 1994). The PAS (Asp74, Tyr124, Ser125, Trp286, Tyr337 and Tyr341) is located near the 
opening of the gorge, which is believed to attract and facilitate ACh movement into the gorge (Massoulié et al. 1993; Sussman et al. 1991). Upon binding, the carbonyl group of ACh reacts with the CAS of AChE (Figure 1-8). This reaction rapidly generates two products: choline and acetylated AChE (Quinn 1987). As an intermediate product, acetylated AChE is unstable in water and is readily hydrolyzed (Quinn 1987; Taylor and Radic 1994). The final products of one reaction cycle (Figure 1-8) are choline and acetic acid (Quinn 1987; Taylor and Radic 1994).
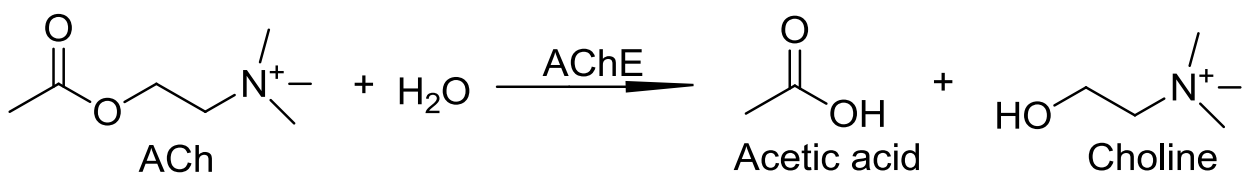

Figure 1-8. Acetylcholine hydrolysis by acetylcholinesterase.

\subsection{Mode of Action And Pharmacokinetics of Carbamate and Organophosphate Compounds on the Acetylcholine System}

$\mathrm{AChE}$ reacts with carbamate compounds in a similar way as its catalytic hydrolysis of ACh (Figure 1-9) (Wilson et al. 1960). After diffusing into the gorge and reaching the catalytic site of $\mathrm{AChE}$, carbamate compounds first form a non-colvent intermediate with $\mathrm{AChE}$, which is a Michaelis Complex (Radic and Taylor 2006). The rate of this step is determined by two constants, which are the association rate constant, $k_{l}$ and the dissociation rate constant, $k_{-1}$. The equilibrium constant of intermediate product formation is $K_{d}$ (unit is $\mathrm{M}^{-1}, \mathrm{mM}^{-1}$, etc.) which equals $k_{l} / k_{-1}$ (Aldridge and Reiner 1972; Richardson 1992). The carbonyl group of the carbamate then attacks the serine hydroxyl group at the $\mathrm{AChE}$ catalytic site, forming the carbamoylated $\mathrm{AChE}$ and one leaving

group. This serine carbamoylation step is reversible and $k_{c}$, the rate constant (units are $\min ^{-1}, \sec ^{-1}$, etc.), is used to describe the rate of this reaction step (Aldridge and Reiner 1972). Since most of the carbamate compounds (except the thiocarbamate group) can inhibit AChE without metabolic pre- 
activation, once the carbamate compounds reach the catalytic site of AChE, the carbamoylation proceeds. Therefore, the rate of intermediate product formation determines the rate of the carbamoylation process and is directly correlated with the inhibitory capacity of carbamate, which means the $\mathrm{K}_{d}$ value can be used to mostly describe the inhibitory activity.

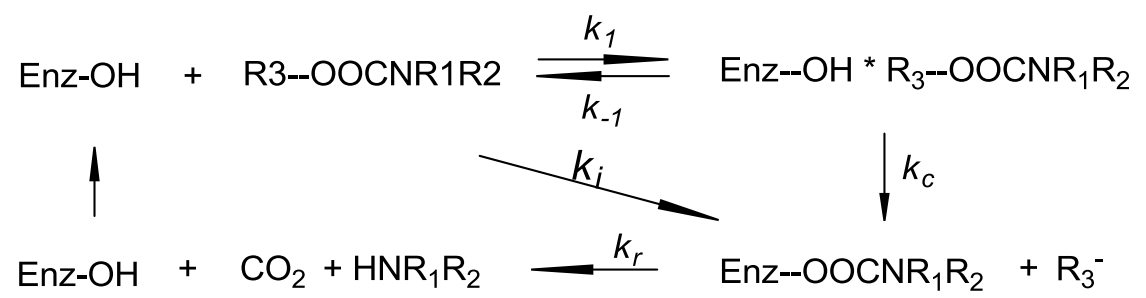

Figure 1-9. Diagram demonstrating the reaction between serine hydrolase (acetylcholinesterase) and a carbamate.

The bimolecular rate constant of inhibition, $k_{i}\left(\mathrm{mM}^{-1} \mathrm{~min}^{-1}\right)$, is used to quantify the inhibition potency of carbamate compounds (Aldridge and Reiner 1972; Main 1964). Because $k_{i}$ is equal to $k_{c} / K_{d}$, it describes both the site affinity and carbamoylation rate of AChE, and is specific for each carbamate compound (Fukuto 1990; Main 1964). The more potently a carbamate compound binds and the faster the carbamoylation rate is, the bigger the $k_{i}$ value will be (Fukuto 1990). Mathematically, the $k_{i}$ value is determined by using the equation that $\ln \left(\mathrm{A}_{\mathrm{n}} / \mathrm{A}_{0}\right)=-k_{i}^{*}[\operatorname{Inh}]^{*} t$, where $\mathrm{A}_{\mathrm{n}}$ and $\mathrm{A}_{0}$ are the remaining and initial activity of $\mathrm{AChE}$, respectively, while $t$ is the time AChE interacts with carbamates (Radic and Taylor 2006). [Inh] means the concentration of AChE inhibitor. By replacing different chemical groups on carbamate compounds, the $k_{i}$ value is subject to change because both Michaelis Complex formation and carbamoylation rate are changed (Fukuto 1990; Sultatos 2006). This structure-activity property has been advantageous in dealing with different problems such as pesticide development (Sultatos 2006), which will be discussed later.

Finally, the carbamoylated AChE is reactivated through slow hydrolysis by water, which is characterized by the reactivation constant, $k_{r}$ (Aldridge and Reiner 1972; Fukuto 1990; Segel 1975). 
Unlike acetylated $\mathrm{AChE}$, the carbamoylated $\mathrm{AChE}$ is more stable and the decarbamoylation process usually takes about an hour (Fukuto 1990; Main 1980). Thus, acetylated AChE has a larger $k_{r}$ value than that of carbamoylated AChE (Fukuto 1990). Similar to AChE's deacetylation process, the final products of one reaction cycle will not change in either quantity or quality of AChE (Thompson and Richardon 2004). Structure-activity property of carbamate can also regulate the rate of water hydrolysis step (Sultatos 2006). For example, compared to its corresponding $N, N$-dimethyl carbamate, $p$-nitrophenyl $N$-monomethyl carbamate has a 7 times larger $k_{r}$ value of $5.4 * 10^{6} \mathrm{M}^{-1} \mathrm{~min}^{-1}$ (Metcalf 1971). A detailed mechanism will be discussed later in this thesis.

Organophosphate compounds are another family of cholinesterase inhibitors. Although different in chemical structure, organophosphates share a similar AChE reaction process with carbamate compounds, and include navigating the gorge and $\mathrm{AChE}$ phosphorylation. However, the value for $k_{r}$ of organophosphate compound is extremely small (Richardson 1992), because phosphorylated $\mathrm{AChE}$ is extraordinarily stable and resistant to water hydrolysis. Compared to 1 hour water hydrolysis for carbamoylated $\mathrm{AChE}$, water hydrolysis of phosphorylated $\mathrm{AChE}$ takes hours to days depending on the structure of the organophosphate compound (Main 1980). By using oxime antidotes, such as 2-PAM and TMB-4 (Wilson and Ginsburg 1955; Wilson et al. 1958), the phosphoryl-serine bond can be broken and dephosphorylation happens. This phenomenon shows mathematically as an increased $k_{r}$ value.

However, if the antidotes are not applied in time, aging may occur, which is a unique characteristic of phosphorylated AChE, but not carbamoylated AChE (Casida and Quistad 2004). The definition of aging is the dealkylation of phosphoryl substituent on the phosphorylated AChE, which strengthens the covalent bond and makes it impossible for water hydrolysis. It has been shown that this aging process is affected by the protonated His 447 of the CAS, a glutamic acid 
residue adjacent to the CAS, and a Trp-86 residue nearby the CAS (Shafferman et al. 1996; Viragh et al. 1997). Once aging occurs, even oxime antidotes can no longer break the phosphoryl-serine bond (Fukuto 1990). In this case, phosphorylated AChE is going to be permanently inhibited and only biological degradation can proceed.

\subsection{Structure-Activity Relationships of Carbamate Insecticides on Acetylcholinesterase}

As mentioned above, by changing the chemical substituents in appropriate places, the pharmacokinetic properties of carbamate compounds can be changed. Steric property is very important for carbamate compounds to access the catalytic site before a covalent bond is formed. Normally, it is believed that the best structure for carbamate should be close to that of ACh (Sultatos 2006; Kolbezen et al. 1954). One example is $m$-isomer of tert-butylphenylmethylcarbamate, which has been shown to have a highly effective anticholinesterase capacity (Kolbezen et al. 1954). As mentioned before, modification of the carbamate chemical structure at appropriate sites can change both carbamoylation and decarbamoylation rate, which mathematically shows an altered $k_{c}, K_{d}, k_{r}$ and $k_{i}$ value. For insecticidal usage, the optimum carbamate compound should have the highest reactivity and selectivity on target insect species. In addition, it is also important for carbamate compounds to possess appropriate physicochemical properties to penetrate cuticle of blood brain barrier.

$\mathrm{N}$-alkyl substituents are responsible for the reaction rate of carbamoylation or in other words, determine the $k_{c}, K_{d}, k_{r}$ value. $N, N$-dimethyl carbamate is less reactive than $N$-monomethyl carbamate because the bulky substituent of the alkyl group on nitrogen blocks the access to catalytic site in the AChE's gorge (Thompson and Richardon 2004). This will cause a decreased rate of binding and reaction and lowered $k_{c}, K_{d}, k_{r}$ value. In this case, as a weak AChE inhibitor with 
slower reaction rate and less significant biological effect, $N, N$-dimethyl carbamate compounds are more often used for clinical therapy purposes, while $\mathrm{N}$-monomethyl carbamate compounds are good insecticides. Representative examples are neostigmine (Komloova et al. 2010) and bendiocarb (PAN Pesticides Database 2000b), which are dimethyl- and monomethyl carbamate compounds respectively. As a dimethyl carbamate compound, neostigmine has a smaller $k_{c}$, bigger $K_{d}$, and smaller $k_{r}$ compared to that of the monomethyl carbamate compounds. On the one hand, the small $k_{c}$ and bigger $K_{d}$ would less likely to cause an acute toxicity on patients who take neostigmine. On the other hand, the smaller $k_{r}$ value allows a persistent AChE inhibition at a moderate dose, which is easier for patients taking neostigmine. However, as an insecticide, bendiocarb displays a bigger $k_{c}$ and smaller $K_{d}$, which cause potent effects on the insect.

$\mathrm{N}$-alkyl substituents also account greatly for the rate of the decarbamoylation step. Research has showed that different carbamoylated forms of $\mathrm{AChE}$ has different susceptibility to hydrolysis (O'Brien 1967). This susceptibility order of carbamoylated AChE is known to be Enz- $\mathrm{COCH}_{3} \gg$ Enz-C(O)NH $\mathrm{NH}_{2}>\mathrm{Enz}-\mathrm{C}(\mathrm{O}) \mathrm{NHCH}_{3}>\mathrm{Enz}-\mathrm{C}(\mathrm{O}) \mathrm{N}\left(\mathrm{CH}_{3}\right)_{2}\left(\mathrm{O}^{\prime}\right.$ Brien 1967). Thus, $N$-alkyl substituents play an important role in carbamate structure-activity relationship, which greatly determines the pharmacodynamics of each carbamate compound.

Generally, in a phenyl carbamate compound, for a given alkyl group substituent (but not the alkoxy groups), the 3- or meta position produces the most active AChE inhibitor, which is followed by the ortho position and para position. Research has showed that the meta-position provides the optimum distance between the carbonyl group and substituent group (Kuhr and Dorough 1976). Either increasing or decreasing this distance lowers the inhibitory potency. The inhibitory potency order of alky group substituent are known to be meta > ortho > para (Kuhr and Dorough 1976). In addition, at a given position on the phenyl ring, increasing the substituent chain size, from 1 carbon 
to 3 carbons, can increase the anticholinesterase capacity. However, any branched chain, which was larger than 4 carbons, is generally going to reduce the inhibitory capacity (Kuhr and Dorough 1976). In conclusion, chemical modification of carbamate compounds will regulate its activity, and appropriate design of carbamate compound will maximize the desired result and minimize undesirable effects.

\subsubsection{Neurotoxic Esterase and OPIDN}

\subsection{Introduction of Neurotoxic Esterase and OPIDN}

Neurotoxic esterase (NTE) is a unique serine hydrolase that responds to different serine covalent inhibitors. NTE is sensitive to neuropathic organophosphate compounds, such as $N, N^{\prime}-$ diisopropyl-phosphorodiamidofluoridate (mipafox) and diisopropylfluorophosphate (DFP) (Figure 1-10) (Johnson 1982).

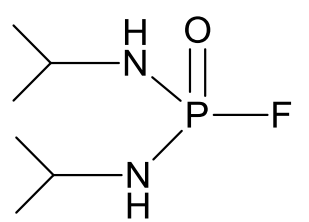

$\mathrm{N}, \mathrm{N}$-diisopropylphosphorodiamidic fluoride

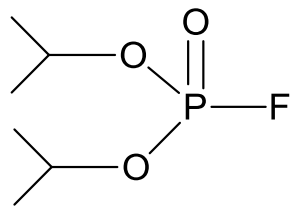

Diisopropyl phosphorofluoridate

Figure 1-10. Structure of Mipafox (N,N'-diisopropylphosphorodiamidic fluoride) (left) and Diisopropylfluorophosphate (DFP) (diisopropyl phosphorofluoridate) (right).

Although distributed in a variety of tissues, such as placenta, spleen, etc. (Williams 1983), NTE has the highest reactivity and quantity in brain in all species that have been examined (Richardson 1992). At the subcellular level, NTE is mainly defined as a membrane associated protein that catalyzes the phosphatidylcholine to glycerophosphocholine deacylation (Richardson 1992). By comparing NTE gene sequences through species, it is known that vertebrate animals, 
invertebrate animals, and microorganisms share highly conserved DNA coding sequence and reading frame organization (Lush et al. 1998). In insects such as Drosophila melanogaster, an NTE homologue called Swiss Cheese Protein (SWS) exists (Kretzschmar et al. 1997). After more than 70\% NTE inhibition, there will be a distal swelling and dying back degeneration of motor and sensory peripheral nerves in both peripheral and central (spinal cord) nerves system, which is termed organophosphate-induced delayed neuropathy (OPIDN) (Lotti and Johnson 1980). In insects, the inhibition of SWS causes the same histological changes, presenting as glial over-wrapping and neurodegeneration (Kretzschmar et al. 1997).

The first human cases of OPIDN occurred in 1920 in the United States because of OP poisoning (Smith et al. 1930). It was reported that after consumption of a beverage called "Jamaica Ginger," more than 30,000 people developed a specific "Ginger paralysis" which made them unable to use their hands and feet. Later, a chemical named tri-o-tolyl phosphate (TOCP) was isolated from this drink, which was shown to be responsible for Ginger paralysis (Goldfain 1930; Smith et al. 1930). Later results strongly suggested that NTE is the target site for TOCP, the inhibition of which was the major underlying mechanism of OPIDN (Johnson 1974; 1990). Subsequently, more neuropathic organophosphate compounds were found and NTE inhibition that correlated with OPIDN was demonstrated in other animal species, such as rodent, feline, and avian. After organophosphate dosing, they all presented the classical OPIDN patho-histological and behavior changes (Bouldin and Cavanagh 1979b; Carboni et al. 1992; Drakontides et al. 1982; Stumpf et al. 1989; Veronesi 1984). Particularly, compared to the mammalian rodent model, the avian (chicken) model expressed the highest sensitivity to neuropathic organophosphate compounds and is the best association model between nerve lesions and locomotion deficits (Dudek et al. 1979; Dudek and Richardson 1982). 


\subsection{Mode of Action and Pharmacokinetics of Carbamate and Organophosphate Compounds on NTE}

As a serine hydrolase, all carbamate and organophosphate compounds could potentially access and covalently bind to the catalytic site of NTE, resulting in its functional inhibition (Clothier and Johnson 1980; Johnson 1982). However, among all the NTE inhibitors, scientists used to believe only certain organophosphate compounds can induce OPIDN, which are phosphates, phosphonates and phosphoramidates (Glynn 2006; Moretto and Lotti 2006) (Table 1-1.). Phosphinates, on the other hand, were believed to be safe for NTE (Johnson 1974, Glynn and Johnson 2001) (Table 1-1.). More recently, some carbamate compounds have also been shown to cause delayed neuropathy (Lotti and Moretto 2006; Randall et al. 1997). 
Table 1-1. Structure of neuropathic and non-neuropathic organophosphate compounds.

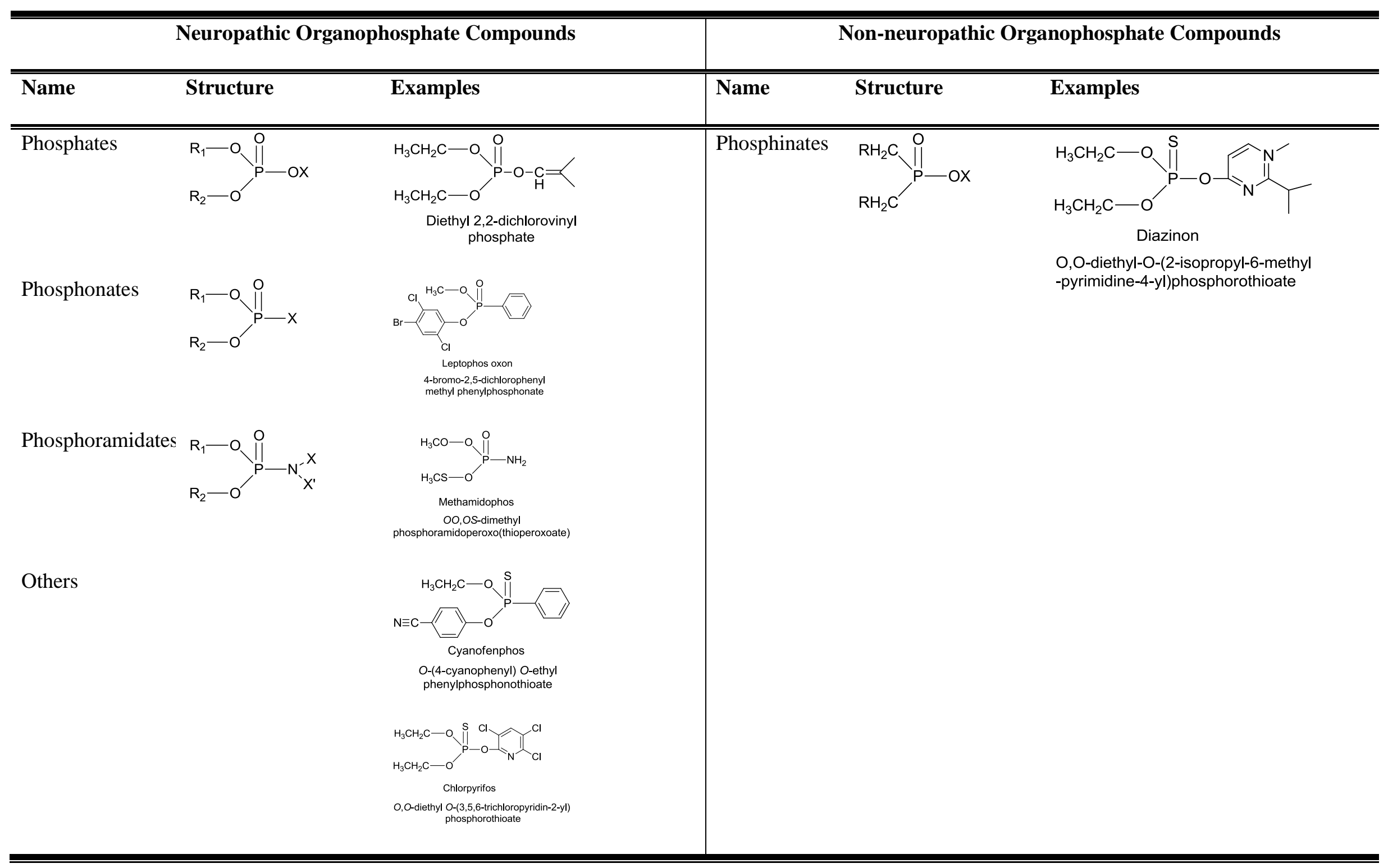


The OPIDN-inducing organophosphate compounds are called neuropathic OPs. Organophosphate compounds such as paraoxon are called non-neuropathic OP because they do not inhibit NTE (Glynn 2006). These non-neuropathic OPs, as well as non-OPIDN inducing carbamate compounds (Johnson 1970), can even protect against OPIDN incidence if administrated to experimental animals before neuropathic organophosphate compounds (Moretto and Lotti 2006). It is believed that neuropathic organophosphate compounds undergo aging after covalent binding, while non-neuropathic covalent NTE inhibitors cannot (Davis et al. 1985; Clothier and Johnson 1980; Johnson 1982; Lotti and Johnson 1980). The aged NTE loses its physiological function, thus leading to axonal degeneration.

For carbamate compounds, the pharmacodynamics of NTE inhibition is the similar to that of AChE inhibition (Moretto and Lotti 2006). After arriving at the catalytic site of NTE, they bind to NTE and form a Michaelis Complex, producing the carbamoylated NTE. Similar to carbamoylated AChE, carbamoylated NTE is more stable than the NTE complex with its natural substrate. However, unlike phosphorylated NTE, carbamoylated NTE can begin to gradually hydrolyze, which usually takes hours, but will eventually restore the active NTE (Moretto and Lotti 2006). All kinetic constants described are the same as that of the AChE carbamoylation processes, and have the same meaning.

For organophosphates, the reaction procedures are the same as that AChE phosphorylation in the early steps (Figure 1-11). First, organophosphate compounds attack the NTE active site, forming a Michaelis Complex, resulting in production of phosphorylated NTE. All kinetic constants described are the similar to those of the AChE carbamoylation processes, and have the same meaning. 


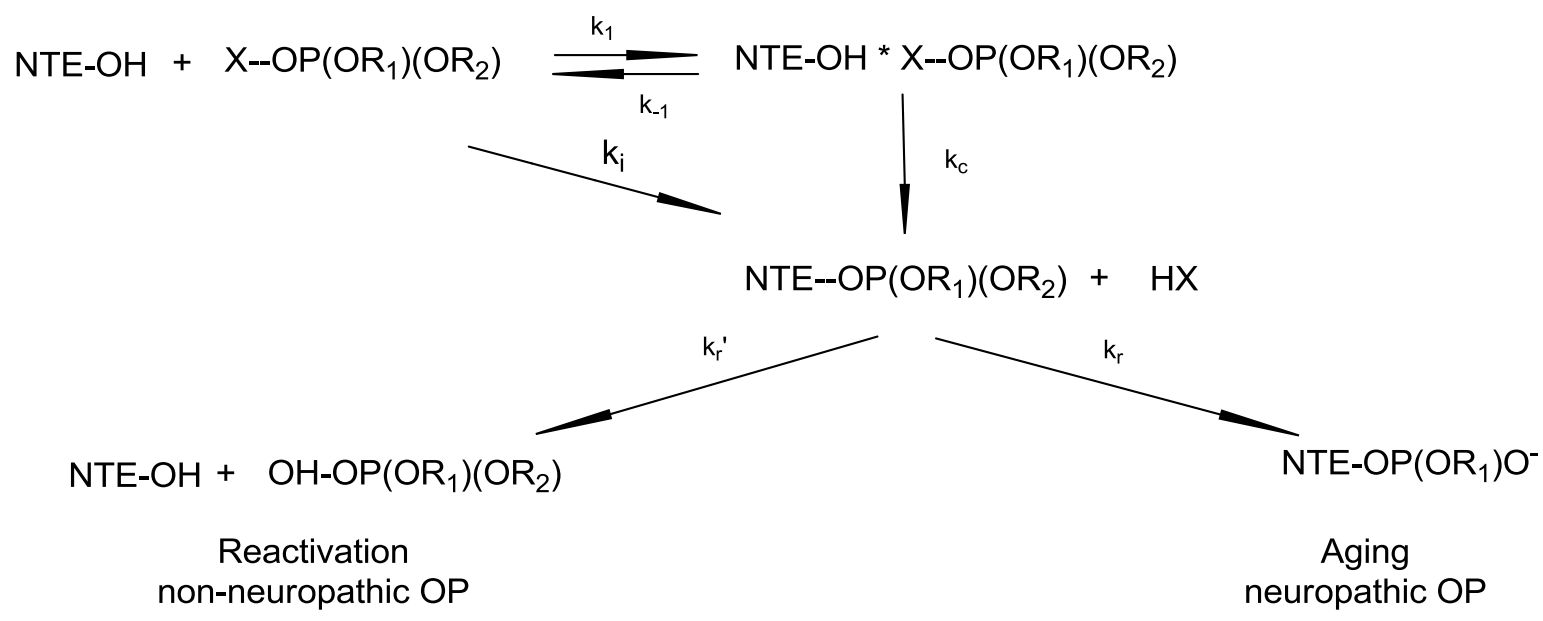

Figure 1-11. Diagram demonstrating the reaction between serine hydrolase (NTE) and different organophosphate compounds. When reacting with neuropathic OP, neurotoxic esterase is phosphorylated and follows the aging pathway. When reacting with non-neuropathic OP, neurotoxic esterase is phosphorylated first, but reactivated later.

However, unlike that of NTE carbamoylation, the pharmacokinetic step of phosphorylated NTE splits into two separate pathways because of the aging capacity difference between neuropathic OP and non-neuropathic OP (Glynn 2006; Moretto and Lotti 2006). For neuropathic OP, which usually contain at least one $-\mathrm{O}$ - or $-\mathrm{NH}$ - substituents linking to phosphorus, further dealkylation on one site on the side chain forms an aged NTE (Glynn and Johnson 2001). Aged NTE does not allow the de-phosphorylation process and both its reactivity and reaction is blocked (Glynn and Johnson 2001). The non-neuropathic OP does not proceed to the aging pathway and allows the slow hydrolysis of phosphoryl bond, which eventually releases the activated NTE. This reactivation still takes days before NTE gets reactivated because phosphorylated NTE is stable and is resistant to water hydrolysis. In this case, $k_{r}$ value equals to 0 for neuropathic OP while $k_{r}{ }^{\prime}$ value is small compared to that of non-neuropathic carbamate compounds.

\subsubsection{Toxicity}

\subsubsection{Toxicity of Carbamate Compounds in Human}


Potent carbamate compounds can cause intoxication in many organs based on the exposure dose and time. After a chronic exposure to carbamate compounds, multiple organ functions and histological organization may be affected, including the central and peripheral nerve, cardiovascular, pulmonary, dermal, endocrine and reproductive systems (Gupta 2006). In situations of acute carbamate intoxication, symptoms are consistent with cholinergic system over-stimulation and expressed as a combination of both nicotinic and muscarinic effects. The classical symptoms are described in humans as SLUDGE (salivation, lacrimation, urination, defecation, gastrointestinal distress and emesis) (Moser 1995; 1999; Moser et al. 1988). In addition, as a serine hydrolase, NTE could also be inhibited by certain carbamate compounds, which eventually cause OPIDN (Lotti and Moretto 2006; Randall et al. 1997),

\subsubsection{Methods to Test Reactivity of Carbamate Compounds}

\subsection{Ellman Assay for Cholinesterase Reactivity}

The most common method for detecting cholinesterase reactivity was introduced by Ellman et al. (1961), which is a chemical cascade reaction based on the Ellman reagent. Ellman reagent, or 5,5'-dithiobis-2-nitrobenzoic acid (DTNB), is a water soluble, colorless, crystalline compound at room temperature. In solution, it is very sensitive to exposure to free sulfhydryl groups. After reaction with the sulfhydryl group, two products are formed, which are a mixed disulfide and 2nitro-5-thiobenzoic acid (TNB). TNB is yellow colored and can be measured by a spectrometer with absorbance at $405 \mathrm{~nm}$ and AChE inhibition is quantified by reduced levels of yellow color.

The free sulfhydryl groups in Ellman Assay come from the product of thiocholine ester substrates of AChE. Just like the steps of ACh hydrolysis, AChE hydrolyzes acetylthiocholine ester and produces free sulfhydryl groups in solution. There are three classical thiocholine ester substrates 
that are still widely used. They are PTCh (propionylthiocholine iodide), BTCh (butyrylthiocholine iodide) and ATCh (acetylthiocholine iodide) (Yamada et al. 2001). Because PTCH, BTCH and ATCh have different properties and reactivity rates, they are used selectively in different cholinesterase testing methods. For human AChE in Ellman Assay, ATCh is the preferred substrate (Reiner et al. 2000). The detailed chemical reaction involved in Ellman Assay is presented below (Figure 1-12):

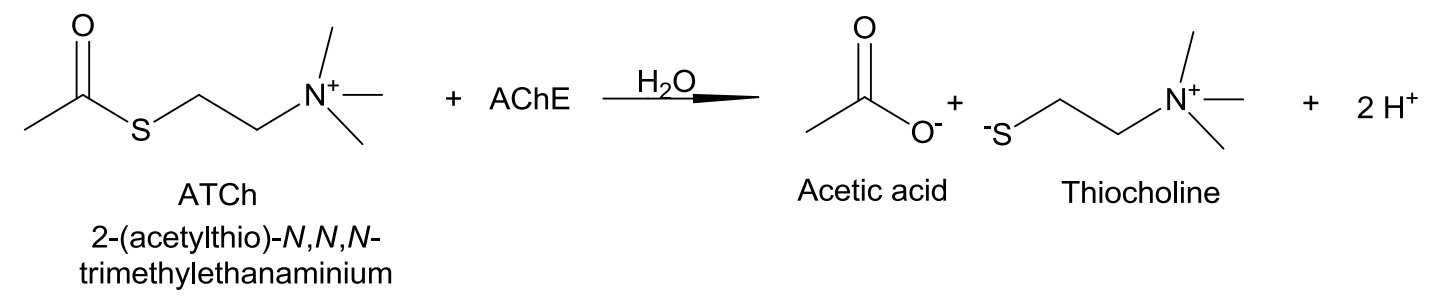

Step 1. ATCh hydrolysis<smiles>O=C(O)c1ccc(SSc2ccc([N+](=O)[O-])c(C(=O)O)c2)cc1C(=O)O</smiles><smiles>C[N+](C)(C)CCS</smiles>

2-carboxy-4-((3-carboxy-4nitrophenyl)disulfanyl)benzoate

Step 2. Disulfide formation

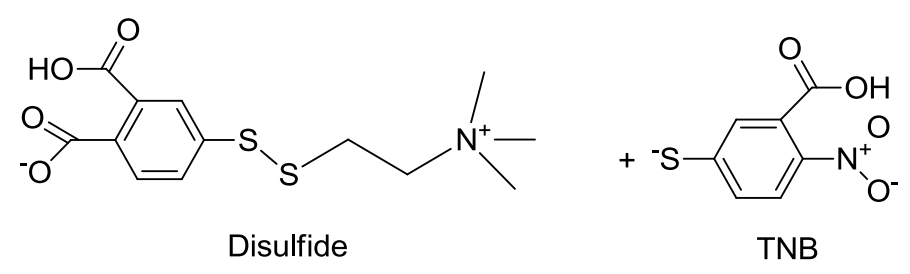

2-carboxy-4-((2-(trimethylammonio) ethyl)disulfanyl)benzoate

3-carboxy-4nitrobenzenethiolate

Figure 1-12. Ellman assay reaction procedures. Step 1. ATCh is added to a solution containing AChE. AChE will hydrolyze ATCh and generate two products, which are thiocholine and acetic acid. Step 2. DTNB reacts with thiocholine to form TNB, which shows a measurable yellow color.

\subsection{Neurotoxic Esterase Assay}

NTE assay was developed and improved by Johnson (Johnson 1969; 1975; 1977). Usually, paraoxon and mipafox will be used as a general esterase inhibitor and neuropathic organophosphate 
compound, respectively. After pre-incubation with paraoxon and paraoxon + mipafox respectively, NTE activity could be obtained by detecting the serine hydrolase reactivity difference between these two samples. The substrate phenyl valerate is hydrolyzed to liberate phenol by NTE. Next, by adding an alkaline solution of potassium ferricyanide, this liberated phenol will react with 4aminoantipyrine, forming the final product called $\mathrm{N}-(1$, 4-benzoquinoneimine)-antipyrine, which is yellow colored and has maximum absorbance at $510 \mathrm{~nm}$ wavelength. Finally, the experiment is stopped by putting the detergent sodium dodecylsulfate (SDS) into the solution (Johnson 1977).

\section{Chapter 2 Experimental Design and Methods}

\subsection{Materials}

Three commercial carbamate insecticides, bendiocarb, carbofuran, and propoxur were donated by or purchased from Nor-AM Chemical Company, Chem-Service, and Mobay Corporation, respectively. All chemicals were at analytical grade, which was $>95 \%$ purity. All novel carbamate insecticides were synthesized and characterized in the laboratory of Dr. Paul R. Carlier, Department of Chemistry, Virginia Polytechnic Institute and State University. The structures of these novel carbamate insecticides are shown below (Table 2-1). Acetylthiocholine iodide (ATCh), 5,5-dithio2,2-nitrobenzoic acid (DTNB), bovine serum albumin (BSA), and TritonX-100 were purchased from Sigma (Sigma-Aldrich Corporation, St. Louis, MO, USA). All chemicals were at analytical grade. Paraoxon and mipafox were obtained from the laboratory of Dr. Marion F. Ehrich. 
Table 2-1. Structure name and chemical name of novel carbamate insecticides that were tested in this study.

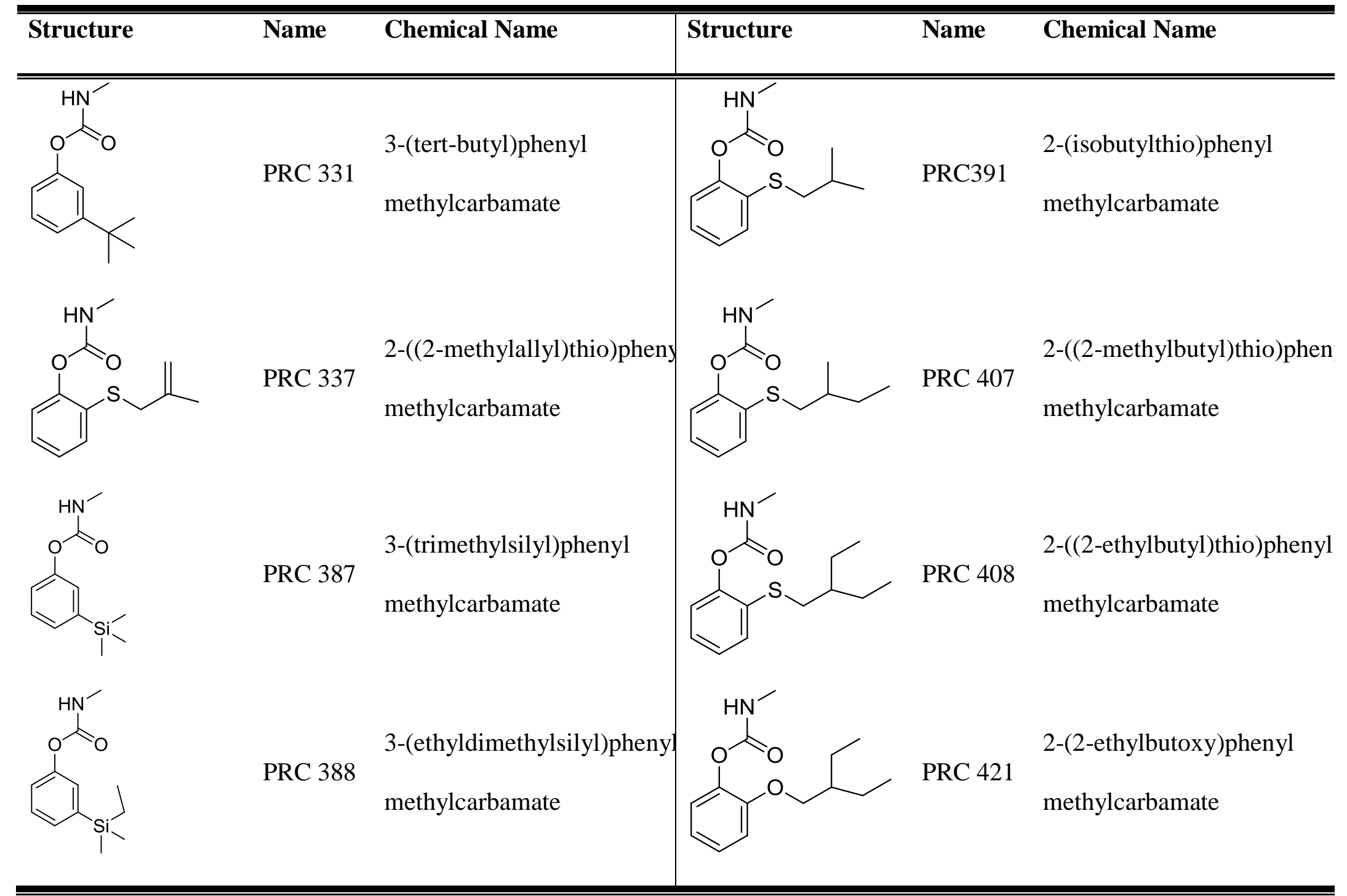

This table demonstrated the structure, general name and chemical name of novel carbamates that were tested in this study. 


\subsection{Animal and Sample Preparation}

\subsubsection{Recombinant Human and Mouse AChE}

Recombinant human and mouse AChE were kindly donated by Dr. Fredrik Ekström, of the Swedish Defense Research Agency. The detailed cloning and expression method can be obtained elsewhere (Ekstrom et al. 2006). After receiving the enzyme in original concentration, a 50-fold dilution and 30-fold dilution was made for recombinant mouse and human $\mathrm{AChE}$, respectively, and aliquots were held at $-80{ }^{\circ} \mathrm{C}$ until use. Each $20 \mathrm{ul}$ of mouse $\mathrm{AChE}$ was mixed with $980 \mathrm{ul}$ ice cold sodium hydrogen phosphate, $\mathrm{pH} 7.8$, containing 3\% Triton-x-100 (Sigma, USA). Each 25 ul human AChE was mixed with $725 \mathrm{ul}$ ice cold sodium hydrogen phosphate, $\mathrm{pH} 7.8$, containing $3 \%$ Triton-x100 (Sigma) was added.

\subsubsection{Hen Brain Homogenate}

Hen brain samples were obtained from Dr. Marion Ehrich. Hens were sacrificed by cervical dislocation, the brain was dissected rapidly on ice, and kept in ice-cold artificial cerebrospinal fluid (ACSF, in mM: NaCl, 124.0; $\mathrm{NaHOC}_{3}, 25.0$; D-glucose, 10.0; KCl, 3.4; $\mathrm{KH}_{2} \mathrm{PO}_{4}, 1.2 ; \mathrm{MgSO}_{4}, 1.0$; $\mathrm{CaCl}_{2}, 2.5 ; \mathrm{pH}$ 7.4). Each $10 \mathrm{mg}$ hen brain was homogenated in $25 \mathrm{ml}$ ice cold sodium hydrogen phosphate, $\mathrm{pH} 7.8$, containing $3 \%$ Triton- $\mathrm{x}-100$. This sample was then stored in a $-80{ }^{\circ} \mathrm{C}$ freezer for use in NTE assays. For Ellman assay, this brain homogenate sample was further centrifuged at $10,000 \mathrm{RPM}, 5000 \mathrm{x} g, 4{ }^{\circ} \mathrm{C}$ for 15 minutes using a Sorvall Fresco refrigerated centrifuge and all the supernatants were transferred to a clean 1.5 Eppendorf tube and stored in a $-80^{\circ} \mathrm{C}$ freezer.

\subsubsection{Electrophorus electricus Acetylcholinesterase}

Recombinant E. electricus AChE (400 U/mg protein) was purchased from Sigma-Aldrich (USA). The enzyme was diluted in $1 \%$ ice cold BSA solution in a ratio of $1.53 \mathrm{mg}$ AChE $: 1.68 \mathrm{ml}$ 
BSA, resulting in a final concentration of $600 \mathrm{U} / \mathrm{ml}$. An additional 801 fold dilution was performed (1.2 ul enzyme solution was added into 960 ul ice cold sodium hydrogen phosphate, $\mathrm{pH}$ 7.8, containing $3 \%$ Triton-x-100. All enzymes preparations were then kept in a $-80^{\circ} \mathrm{C}$ freezer.

\subsubsection{Torpedo californica Homogenate}

Tissue from the electroplaque organ of T. californica was obtained from Aquatic Research Consultants (San Pedro, CA). After rinsing with ice cold sodium hydrogen phosphate, the electroplaque organ was cut into small pieces and $100 \mathrm{mg}$ electroplaque organ tissue was homogenized in $5 \mathrm{ml}$ ice cold sodium hydrogen phosphate, $\mathrm{pH} 7.8$, containing $3 \%$ Triton-x-100. The homogenates were then centrifuged at $10,000 \mathrm{RPM}, 5000 \mathrm{x} g, 4{ }^{\circ} \mathrm{C}$ for 15 minutes using a Sorvall Fresco refrigerated centrifuge. The supernatants were removed and transferred to a clean 1.5 Eppendorf tube and stored in a $-80{ }^{\circ} \mathrm{C}$ freezer.

\subsubsection{Daphnia magna Homogenate}

Living Daphnia magna were purchased from Carolina Biological Supply Company (Burlington, NC). Ninety D. magna were cultured in 1 gallon spring water and fed every other day, with food supplied by the D. magna culture kits from Carolina Biological Supply Company. Natural illumination was used and the light condition was about 12-12 h light-dark period. Culture kits were kept at room temperature, from $20{ }^{\circ} \mathrm{C}$ to $25^{\circ} \mathrm{C}$. Thirty D. magna were homogenized in $10 \mathrm{ml}$ tubes with ice cold sodium hydrogen phosphate, $\mathrm{pH} 7.8$, containing 3\% Triton-x-100. Then the homogenates were centrifuged at 10,000 RPM, $5000 \mathrm{x} g, 4{ }^{\circ} \mathrm{C}$ for 15 minutes using a Sorvall Fresco refrigerated centrifuge. The supernatants were removed and transferred to a clean 1.5 Eppendorf tube and stored in a $-80{ }^{\circ} \mathrm{C}$ freezer. 


\subsubsection{Anopheles gambiae Homogenate}

Frozen female An. gambiae was obtained from An. gambiae lab culture. Ten An. gambiae were homogenized in $10 \mathrm{ml}$ tubes with ice cold sodium hydrogen phosphate, $\mathrm{pH} 7.8$, containing $3 \%$ Triton-x-100. The homogenates were centrifuged at 10,000 RPM, $5000 \times g, 4{ }^{\circ} \mathrm{C}$ for 15 minutes using a Sorvall Fresco refrigerated centrifuge. The supernatants were taken out and transferred to a clean 1.5 Eppendorf tube and stored in a $-80{ }^{\circ} \mathrm{C}$ freezer.

\subsection{Ellman Assay}

Ellman assay (Ellman et al. 1961) was used to measure AChE activity. The 96 well microtiter plate reading spectrophotometer used for Ellman assay is from DYNEX Technologies, Chantilly, Virginia. Enzyme was mixed with 0.1 M sodium hydrogen phosphate buffer, pH 7.8, with six different inhibitors concentration. Each data set was replicated in triplicate. After $10 \mathrm{~min}$ preincubation of AChE with inhibitor, 5,5-dithiobis-(2-nitrobenzoic acid) (DTNB) and acetylthiocholine (ATCh) were added into the well. The hydrolysis of Ellman assay agents was determined in the same way in the absence of enzyme, which was taken as blank and deducted from all wells. The plate was read at $405 \mathrm{~nm}$ wavelength using a spectrophotometer for $10 \mathrm{~min}$ and a raw data sheet was obtained, which indicated the optical density of each well on the microtiter plate.

Then the raw data sheet of the Ellman Assay was processed in Excel ${ }^{\mathrm{TM}}$ software (Microsoft, Redmond, Washington). The activity remaining equation was used and shown below:

$$
\text { Remaining activity }(\%)=\frac{\left(\mathrm{A}_{\mathrm{n}}-\mathrm{A}_{\text {blank }}\right)}{\mathrm{A}_{0}} * 100 \%
$$

Where $A_{n}=$ absorption of each well with carbamate at different concentration

$$
\mathrm{A}_{\text {blank }}=\text { mean value of absorption of blank wells }
$$

$$
\mathrm{A}_{0}=\text { average value of absorption of control wells (i.e., solvent without carbamate) }
$$


All data were then exported to GraphPad Prism ${ }^{\mathrm{TM}} 5.0$ (GraphPad Software, San Diego, CA, USA) for further statistical analysis.

\subsubsection{Dilution Methods for Ellman Assay}

The AChE inhibitors were diluted into 6 different concentrations. Two dilution methods for inhibitors were used, which were: Method 1; a series dilution with a constant DMSO (DWCD) concentrations and Method 2; a series dilution with various DMSO (DW/OCD) concentration. The detailed steps are described below.

\subsubsection{Method 1. A Series Dilution with a Constant DMSO (DWCD) Concentrations Procedures for AChE Assays}

A 0.1 M AChE inhibitor stock solution was made freshly in DMSO before each experiment. A $10 \mathrm{ul}$ aliquot was placed in $990 \mathrm{ul}$ sodium hydrogen phosphate buffer, resulting in a $1 \mathrm{mM}$ inhibitor solution. Then, $100 \mathrm{ul}$ was removed and transferred to $900 \mathrm{ul}$ hydrogen phosphate buffer, which diluted the inhibitor concentration by 10 fold. This series of 10 fold dilutions ( 5 times in all) provides an inhibitor solution range from $0.1 \mathrm{mM}$ to $10 \mathrm{nM}$. On the plate, another 10 fold dilution was performed, which made the final inhibitor concentration from $10 \mathrm{uM}$ to $1 \mathrm{nM}$. The DMSO concentration varied in this case, which was $1 \%, 0.1 \%, 0.01 \%, 0.001 \%, 0.0001 \%, 0.00001 \%$ for aliquot 1 to 6 . The detailed diagram is shown below (Figure 2-1): 


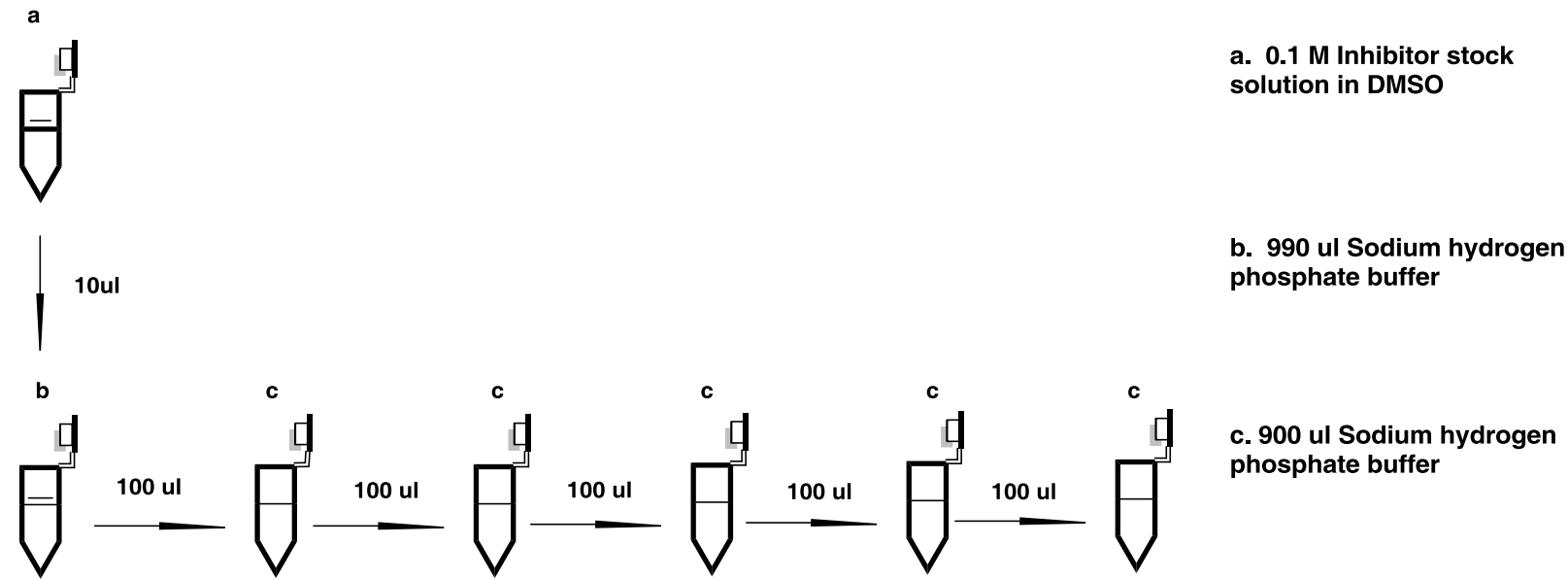

Figure 2-1. The procedure of dilution without constant DMSO concentration method for Ellman assay. The aliquot (a) represented $\mathrm{AChE}$ inhibitor at $0.1 \mathrm{M}$ concentration in DMSO. First, $10 \mathrm{ul}$ was transferred from the stock solution in the aliquot (a) into the aliquot (b) containing 990 ul sodium hydrogen phosphate buffer, which diluted the stock solution by 100 fold. Then 100 ul from aliquot (b) was transferred into the aliquot (c) with 900 ul sodium hydrogen phosphate buffer, which further diluted the solution by 10 fold. Repeating this step 5 times yields a series of AChE inhibitor solutions with a 10 fold difference in adjacent aliquots. The final concentration in aliquot (b) and (c) ranged from $1 \mathrm{mM}$ to10 $\mathrm{nM}$.

\subsubsection{Method 2. A Series Dilution with Various DMSO (DW/OCD) Concentrations} Procedures for AChE Assays

A stock solution of $0.1 \mathrm{M}$ inhibitor was made freshly in DMSO before each experiment. Then, $5 \mathrm{ul}$ inhibitor solution was removed and placed in $45 \mathrm{ul}$ 100\% DMSO. This step was repeated 4 more times and the final products were 5 inhibitor stock solutions with a 10 fold concentration difference. Then a $10 \mathrm{ul}$ inhibitor solution was transferred into $990 \mathrm{ul}$ sodium hydrogen phosphate buffer. The final concentration of inhibitor ranged from $1 \mathrm{mM}$ to $10 \mathrm{nM}$ and $0.1 \mathrm{mM}$ to $1 \mathrm{nM}$ in the final aliquot and on the 96-well plate, respectively; the dilution series contained 10 fold differences. The DMSO concentration was a constant $1 \%$ in the aliquot (c) and $0.1 \%$ on plate. A detailed diagram is shown below (Figure 2-2): 


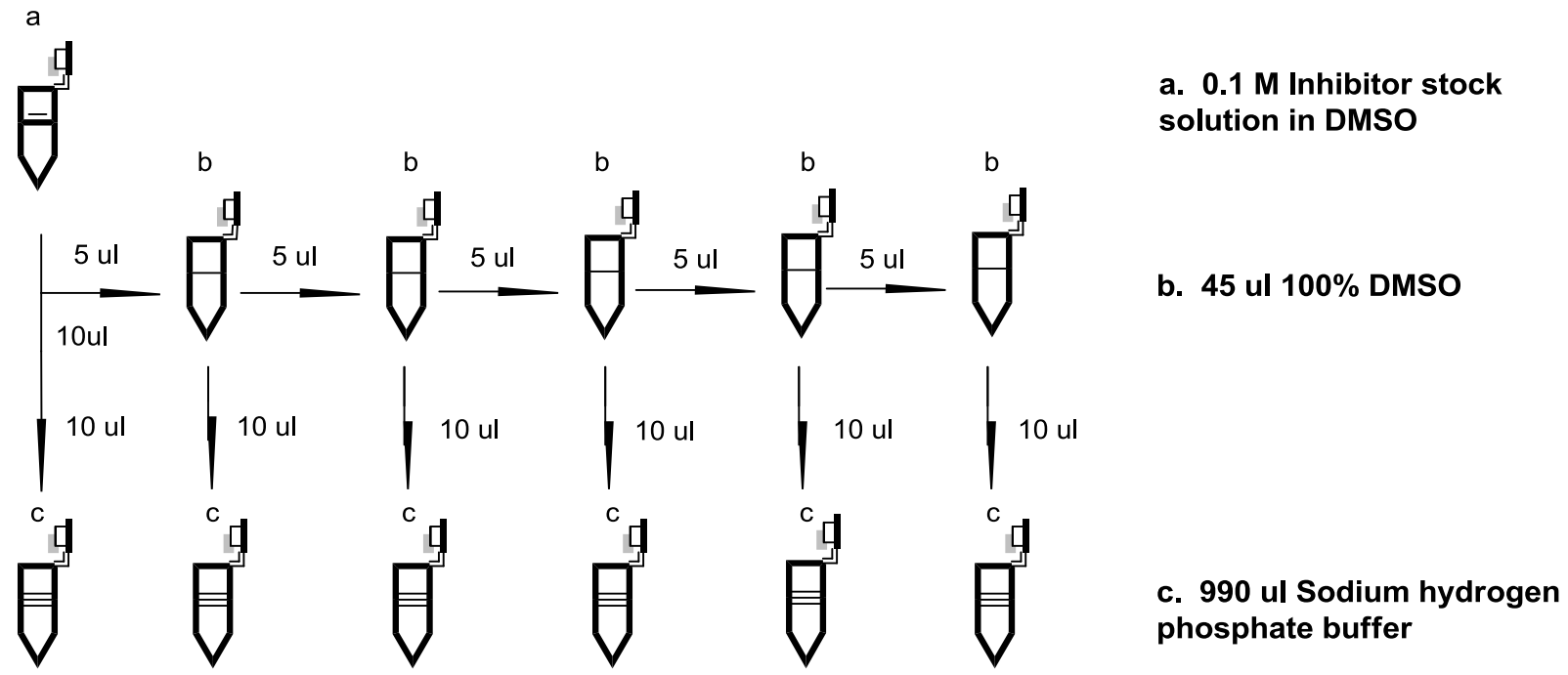

Figure 2-2. The procedure of dilution with constant DMSO concentration method for Ellman assay. The aliquot (a) represents $\mathrm{AChE}$ inhibitor at $0.1 \mathrm{M}$ concentration in DMSO. First, $5 \mathrm{ul}$ inhibitor solution was transferred from the stock solution into the aliquot (b) with 45 ul 100\% DMSO, which diluted the stock solution by 10 fold. Then, 5 ul inhibitor solution was transferred from it into the second aliquot (b) with 45 ul DMSO, which further diluted the solution by 10 fold. Repeating this step 5 times creates a series of $\mathrm{AChE}$ inhibitor solutions with a 10-fold difference in the adjacent aliquot; the concentration of which varied from $10 \mathrm{mM}$ to $1 \mathrm{uM}$. The DMSO remained at 100\%. A $10 \mathrm{ul}$ inhibitor solution from aliquots (a) and (b) were further transferred into the corresponding aliquots (c), which contained $990 \mathrm{ul}$ sodium hydrogen phosphate buffer. 100 fold dilution was made for both inhibitor and DMSO. The final concentration in the aliquots (c) ranged from $1 \mathrm{mM}$ to $10 \mathrm{nM}$, and each had a constant DMSO concentration at $1 \%$.

\subsection{Neuropathy Target Esterase (NTE) Assay}

The NTE assay was performed by the procedures of Johnson (1977). Initially, different test chemicals, such as carbamates, diisopropylphosphorofluoridate (DFP), and DMSO alone, were incubated with hen brain homogenate for $20 \mathrm{~min}$ at room temperature. Then the samples were incubated with paraoxon $(50 \mathrm{uM})$ only or paraoxon $(50 \mathrm{uM})$ plus mipafox $(6.4 \mathrm{uM})$ for $20 \mathrm{~min}$ in the assay buffer (50 mM Tris- $0.2 \mathrm{mM}$ EDTA, $\mathrm{pH} 8.0)$ at $37{ }^{\circ} \mathrm{C}$. Following incubation with phenyl valerate $(0.3 \mathrm{mM})$ for $15 \mathrm{~min}$ at $37{ }^{\circ} \mathrm{C}$, the released phenol was analyzed by coupling with $0.4 \%$ potassium ferricyanide and SDS-aminoantipyrine (de-ionized water contains 5\% sodium lauryl sulfate, $0.02 \%$ 4-aminoantipyrine, $0.50 \mathrm{M}$ Tris) and measured in the spectrophotometer at $510 \mathrm{~nm}$. 
The value from the paraoxon only group (inhibit esterase other than NTE) was deducted from the paraoxon + mipafox group (which inhibited all esterases), giving the activity of NTE. Each remaining NTE activity value was estimated from at least 5 replicates.

In the NTE assay Excel ${ }^{\mathrm{TM}}$ spreadsheet, four sets of absorbance value were obtained from each 96 well plate, which were $A_{\text {blank }}, A_{\text {control}}, A_{\text {paraoxon }}$ and $A_{\text {mipafox+paraoxon. The remaining activity }}$ efficacy was obtained by using the equation shown below:

$$
\text { Remaining activity efficacy }(\%)=\frac{\left.\left(A_{\text {paraoxon }}-A_{\text {mipafox+paraoxon }}\right)-A_{\text {blank }}\right)}{A_{\text {control }}}
$$

Where $A_{\text {blank }}=$ mean value of absorption of blank well

$\mathrm{A}_{\text {control }}=$ mean value of absoption of well where sample was only incubated with solvent DMSO $\mathrm{A}_{\text {paraoxon }}=$ absorption of each well incubated with paraoxon and carbamate $\mathrm{A}_{\text {mipafox+paraoxon. }}=$ absorption of each well incubated with paraoxon, mipafox and carbamate All calculations were done in Excel and exported to GraphPad Prism ${ }^{\mathrm{TM}} 5.0$ (GraphPad Software, San Diego, CA, USA) later for further statistical analysis.

\subsection{In vivo D. magna Aquatic Toxicity Bioassay ( $\left.\mathrm{LC}_{50}\right)$}

Ten Adult D. magna were put in $10 \mathrm{ml}$ of spring water ( $\mathrm{pH} 7.3$ to 7.8 ), which come with the D. magna culture kits (Carolina Biological Supply Company). Six concentrations of each carbamate as well as one control group using solvent only were used for each experiment. Serial dilution of carbamate insecticides from $0.1 \mathrm{M}$ stock solution was used to make all dosing solutions; final concentrations ranged from $10 \mathrm{mM}$ to $0.1 \mathrm{nM}$. After $24 \mathrm{~h}$, the mortality rate was read in all containers.

Abbott's formula (Abbott 1925) was used to correct bioassay data for control mortality. The equation was shown below. 


$$
\mathrm{P}_{\text {corr }}=\frac{\mathrm{P}_{\text {exp }}-\mathrm{P}_{\text {control }}}{1-\mathrm{P}_{\text {control }}}
$$

Where $\mathrm{P}_{\exp }=$ the survival number of D. magna in carbamate containing container $\mathrm{P}_{\text {control }}=$ the survival number of D. magna in carbamate-free (with DMSO) container

All calculation was done in Excel ${ }^{\mathrm{TM}}$ and exported to GraphPad Prism ${ }^{\mathrm{TM}} 5.0$ (GraphPad Software, San Diego, CA, USA) later for further statistical analysis.

\subsection{Statistical Analysis}

GraphPad Prism ${ }^{\mathrm{TM}} 5.0$ (GraphPad Software, San Diego, CA, USA) software was used on all data for statistical test.

For the Ellman assay and the in vivo D. magna bioassay, the $\mathrm{IC}_{50}$ and $\mathrm{LC}_{50}$ values, respectively, were obtained from the sigmoid curve generated by using the nonlinear regression equation as shown below:

$$
\begin{gathered}
\mathrm{y}=\text { Bottom }+(\text { Top-Bottom }) /\left(1+10^{\wedge}\left(\left(\operatorname{LogLC} C_{50}-\mathrm{x}\right) * \text { Hill slope }\right)\right) \\
\text { Where } \mathrm{x}=\text { the logarithm of the concentration of carbamate } \\
\qquad \mathrm{y}=\text { the } \% \text { of control response }
\end{gathered}
$$

Then, either the $\mathrm{IC}_{50}$ or $\mathrm{LC}_{50}$ mean value were obtained from replicate assays and compared by using a two-tailed student $t$-test. Significant difference was defined by whether $P$ value was less than 0.05 .

For enzyme pharmacological comparisons, all $\mathrm{IC}_{50}$ data were first converted into their corresponding $\log _{10}$ value. After being imported into the GraphPad Prism ${ }^{\mathrm{TM}} 5.0$, the data were fitted into a line with linear regression. $\mathrm{R}^{2}$ (the coefficient of determination) was obtained. Then the data were further compared using one-way ANOVA with Dunnett's test for significance between different groups $(P<0.05)$. 
For NTE results, single point enzyme activity of controls and pesticide-exposed groups was used to calculate a group mean for each carbamate insecticide and compared using an ANOVA with Dunnett's test for significance between treatment means and a control $(P<0.05)$.

\subsection{Multiple Sequence Alignment}

Multiple sequence alignment of 'acetylcholinesterase protein sequence' was downloaded in FASTA format from the NCBI (The National Center for Biotechnology Information, http://www.ncbi.nlm.nih.gov/) for mouse, human, hen, T. californica and E. electricus. The protein sequence used was the precursor of the AChE. All the protein sequences were then imported into the ClustalW2EMBL-EBI (The European Molecular Biology Laboratory European Bioinformatics Institute, http://www.ebi.ac.uk/Tools/msa/clustalw2/). The results, including multiple sequence alignment, results summary, and phylogram tree were automatically generated. 


\section{Chapter 3: Results}

\subsection{Assay Validation for Comparison with Previous Results}

Initially, I compared my results with historical data, to verify the accuracy of procedures and equipment. I used three different AChE enzyme sources, which were untreated P1 or P2 (pelleted after one or two centrifugations) male ICR mouse brain cortex homogenate, recombinant mouse, and recombinant human AChE. I tested them with nine commercial carbamate insecticides, using Method 1, DW/OCD method: series dilution without constant DMSO concentrations, which varied from $0.1 \%$ to $0.00001 \%$. 

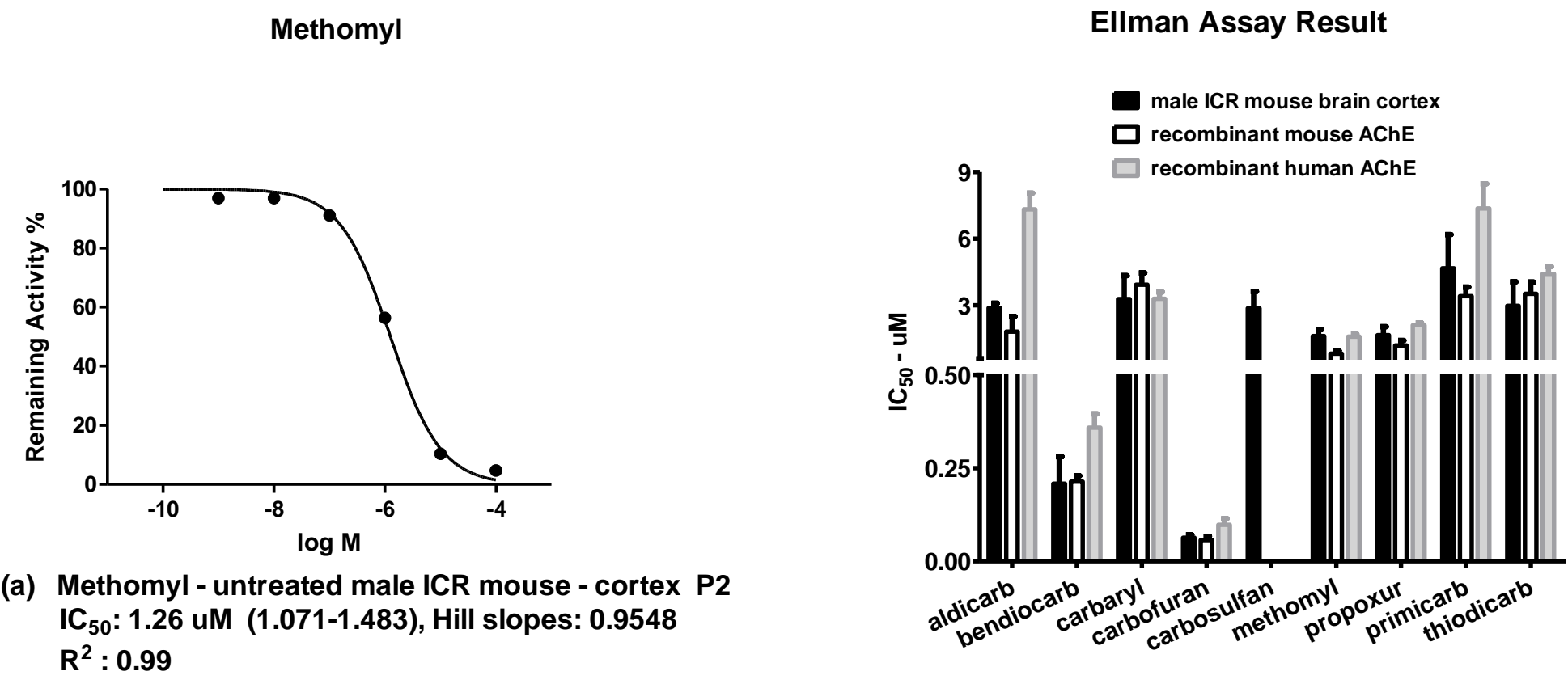

(b) Commercial carbamate insecticides tested

Figure 3-1. Ellman Assay results using dilution without constant DMSO concentration. (a) One example of data from the Ellman Assay. Methomyl was tested on untreated male ICR mouse brain homogenate. Six data points were input into GraphPad Prism ${ }^{\mathrm{TM}} 5.0$ and a sigmoidal curve was obtained. $\mathrm{IC}_{50}$, Hill slope and $\mathrm{R}^{2}$ were automatically generated by this software. (b) $\mathrm{IC}_{50}$ values were obtained from 9 commercial carbamate insecticides on three different non-target vertebrate $\mathrm{AChE}$ sources. The data of each carbamate were repeated at least 4 times. One-way ANOVA test (Turkey) was conducted and no significant difference was detected 
Table 3-1. IC $_{50}$ obtained from 9 commercial carbamate insecticides tested on untreated male ICR mouse brain cortex homogenate, recombinant mouse, and recombinant human acetylcholinesterase. Dilution without constant DMSO concentration dilution method was used for Ellman assay dilution.

\begin{tabular}{|c|c|c|c|c|c|c|c|c|c|}
\hline \multicolumn{2}{|c|}{$\mathrm{IC}_{50}(\mathrm{nM})$} & Aldicarb & Bendiocarb & Carbaryl & Carbofuran & Methomyl & Propoxur & Pirimicarb & Thiodicarb \\
\hline \multirow{4}{*}{$\begin{array}{l}\text { ICR mouse } \\
\text { brain cortex }\end{array}$} & Mean & 2874 & 208.6 & 3274 & 63.06 & 1602 & 1649 & 4665 & 2970 \\
\hline & S.E.M & \pm 69 & \pm 32 & \pm 224.8 & \pm 2.97 & \pm 150.2 & \pm 111.7 & \pm 761.1 & \pm 545.3 \\
\hline & $\begin{array}{c}\text { Hill } \\
\text { slope }\end{array}$ & -1.12 & -1.26 & -1.15 & -1.09 & -1.13 & -1.13 & -1.18 & -0.68 \\
\hline & $\mathbf{R}^{2}$ & 0.99 & 0.99 & 0.99 & 0.99 & 0.99 & 0.99 & 0.99 & 0.99 \\
\hline \multirow{4}{*}{$\begin{array}{l}\text { Recombinant } \\
\text { mouse AChE }\end{array}$} & Mean & 1808 & 214 & 3922 & 57 & 808.1 & 1183 & 3405 & 3511 \\
\hline & S.E.M & \pm 218.7 & \pm 6.398 & \pm 139.9 & \pm 3.76 & \pm 50.79 & \pm 73.74 & \pm 146.8 & \pm 188.2 \\
\hline & $\begin{array}{c}\text { Hill } \\
\text { slope }\end{array}$ & -1.07 & -1.28 & -1.03 & -1.21 & -1.13 & -1.29 & -1.22 & -0.85 \\
\hline & $\mathbf{R}^{2}$ & 0.99 & 0.99 & 0.99 & 0.99 & 0.99 & 0.99 & 0.99 & 0.99 \\
\hline \multirow{4}{*}{$\begin{array}{l}\text { Recombinant } \\
\text { human AChE }\end{array}$} & Mean & 7317 & 359 & 3292 & 97.9 & 1583 & 2094 & 7358 & 4413 \\
\hline & S.E.M & \pm 297.8 & \pm 16.23 & \pm 89.44 & \pm 6.88 & \pm 60.19 & \pm 40.29 & \pm 558 & \pm 165.2 \\
\hline & $\begin{array}{l}\text { Hill } \\
\text { slope }\end{array}$ & -1.04 & -1.28 & -1.21 & -1.20 & -1.12 & -1.32 & -1.22 & -0.77 \\
\hline & $\mathbf{R}^{2}$ & 0.99 & 0.99 & 0.99 & 0.99 & 0.99 & 0.99 & 0.99 & 0.99 \\
\hline
\end{tabular}

\footnotetext{
All data were analyzed by using column statistics in GraphPad Prism ${ }^{\mathrm{TM}} 5.0$. The data of each carbamate were collected from experiments repeated at
} least for 4 times. 
Initial results obtained from using the DW/OCD method provided values of $50 \% \mathrm{AChE}$ inhibition rates $\left(\mathrm{IC}_{50}\right)$ (Figure 3-1, Table 3-1). The $\mathrm{IC}_{50}$ of these commercial carbamates ranged from $57 \mathrm{nM}$ for recombinant mouse $\mathrm{AChE}$ with carbofuran, to $7358 \mathrm{nM}$ for recombinant human AChE with pirimicarb. Carbofuran consistently had the smallest $\mathrm{IC}_{50}$ throughout all three vertebrate AChEs. For both ICR mouse brain cortex homogenate and recombinant human AChE, the greatest $\mathrm{IC}_{50}$ values were obtained when tested with pirimicarb. For recombinant mouse $\mathrm{AChE}$, the highest $\mathrm{IC}_{50}$ was obtained when tested with thiodicarb. The $\mathrm{R}^{2}$ value of all experiments were consistently near 0.99. The value of Hill slope varied from 1.32 (recombinant human AChE + propoxur) to 0.68 (ICR mouse brain cortex homogenate + thiodicarb) and the mean value of it is -1.12 . These results indicated that the DW/OCD dilution method was reliable when testing commercial carbamates with the untreated male ICR mouse brain cortex homogenate, recombinant mouse, and recombinant human AChE sample. In addition, AChE activity level and pattern between recombinant mouse AChE and male ICR mouse brain cortex homogenate were well correlated (Figure 3-2). Based on the $\mathrm{IC}_{50}$ value tested with the commercial carbamates, a well-fitted linear regression line was obtained and the slope and $\mathrm{R}^{2}$ of the line was 0.99 and 0.96 , respectively. 


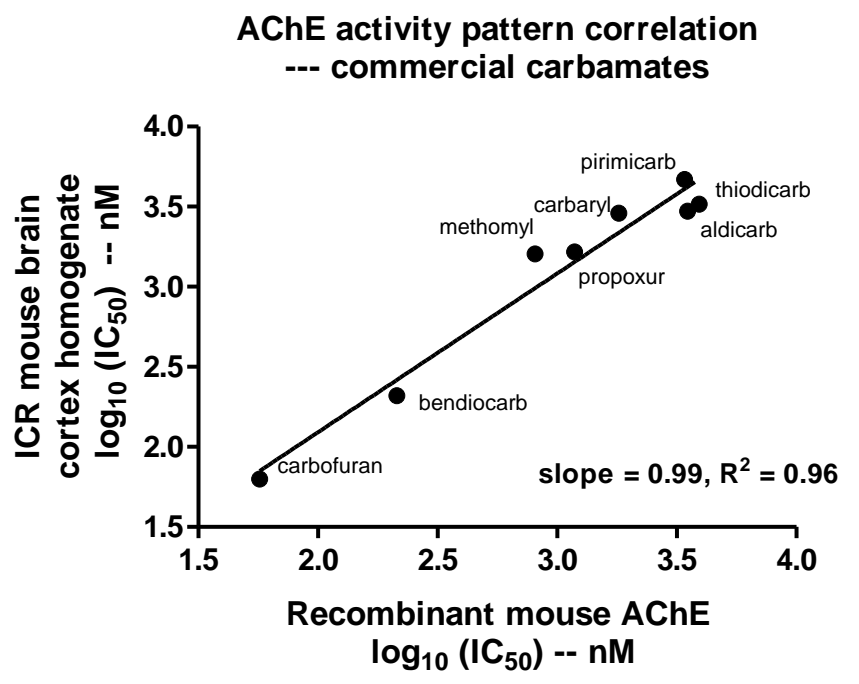

Figure 3-2. Comparison of regression correlation of $\mathrm{IC}_{50}$ (commercial carbamates) between ICR mouse brain homogenate and recombinant mouse acetylcholinesterase. (GraphPad PrismTM5.0 software).

\subsection{Solvent Effect on Ellman Assay}

However, when I applied the same procedures to the novel carbamate insecticides, I found that all novel carbamates, except PRC391, using the DW/OCD method, did not give results in line with classical enzyme-inhibitor interactions (Figure 3-3). According to the data points from Ellman Assay, as shown above in Figure 3-3a, only 60\% of the control AChE activity was reached when the concentration of PRC331 reached $10^{-12} \mathrm{M}$. In this case, the sigmoidal curve was not accurately formed. Although the Prism ${ }^{\mathrm{TM}} 5.0$ still reported $\mathrm{IC}_{50}$, Hill slope and $\mathrm{R}^{2}$, I believed that this data was not reliable. I further diluted the concentration to $10^{-16} \mathrm{M}$ and ran a separate experiment. However, I still failed to fit all data points into one curve (Figure 3-3b). Base on the curve from Figure 18b, the Prism 5.0 cannot obtain a valid $\mathrm{IC}_{50}$ value and the reported Hill slope was also not reasonable, which was -0.043 . In addition, I found that data points formed a plateau from $10^{-7} \mathrm{M}$ to $10^{-12} \mathrm{M}$ and reached $100 \%$ at $10^{-14} \mathrm{M}$. 
PRC 331

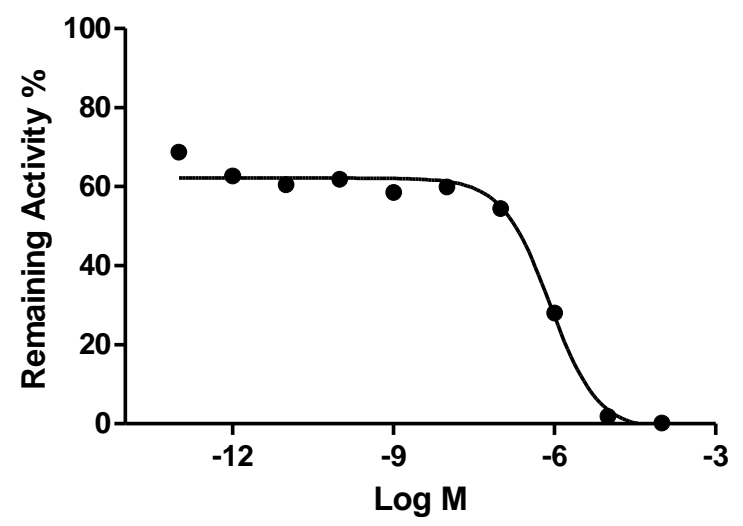

a. Recombinant human AChE $\mathrm{IC}_{50}: 0.82 \mathrm{uM}(0.66 \mathrm{uM}$ to $1.0 \mathrm{uM})$ Hill slope: $-0.97, R^{2}: 0.99$
PRC 331

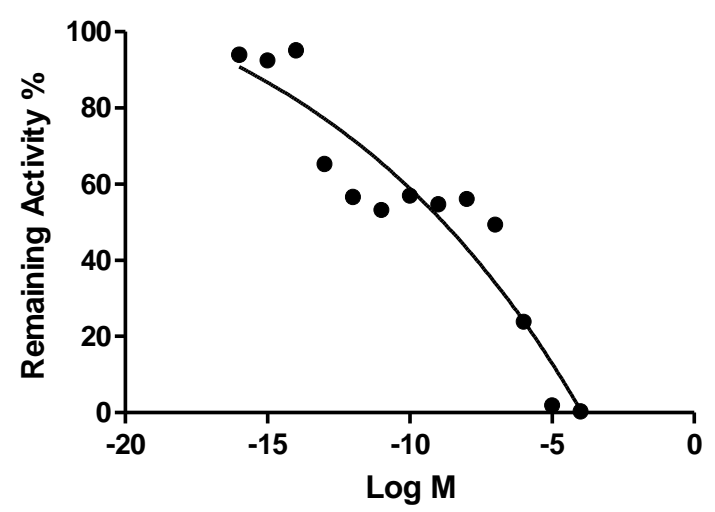

b. Recombinant human AChE $\mathrm{IC}_{50}$ : no answer from Prism 5.0 Hill slope: -0.04346, $\mathbf{R}^{2}: 0.89$

PRC 331

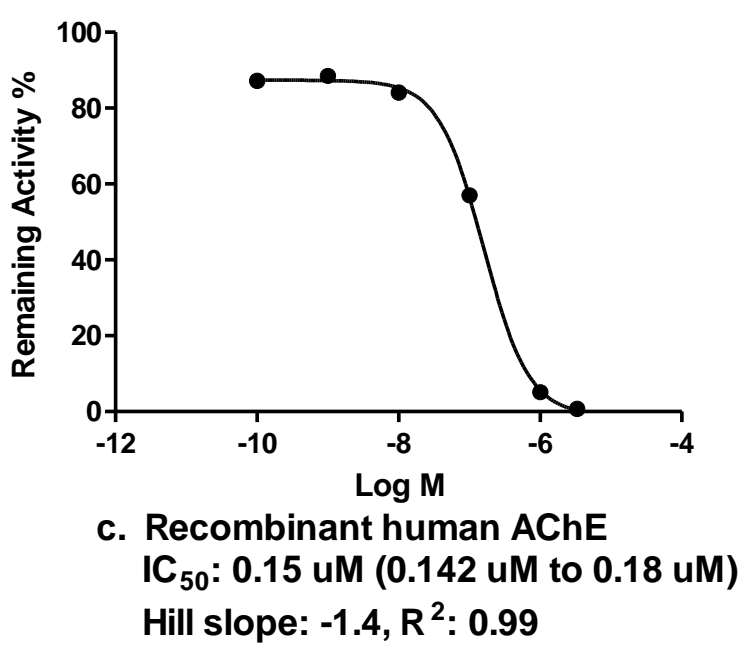

Figure 3-3. Examples of DW/OCD results of the novel carbamate insecticides. PRC331 gave unusual results for $\mathrm{IC}_{50}$ and Hill slope for Ellman assay, tested on recombinant human $\mathrm{AChE}(\mathrm{a}, \mathrm{b})$. However, when using dilution with constant DMSO concentration for Ellman assay, an accurate sigmoidal curve was obtained (c).

By using the DW/OCD method, the novel carbamate insecticides would form a thick film on the sodium-phosphate buffer surface in the aliquot after transferred from $0.1 \mathrm{M}$ stock solution. Thus, the suspension in each aliquot was not well formed and the errors would be magnified by further 
dilution. So, I switched the dilution method to DWCD (dilution method containing constant $0.1 \%$ DMSO), which solved this problem (Figure 3-3c), and was used in all subsequent experiments.

\subsection{AChE Inhibition Rate $\left(\mathrm{IC}_{50}\right)$ Testing}

All 6 non-target species' AChE enzyme activities were tested by using the Ellman Assay with the DWCD dilution method. Eleven carbamates were tested in this series of experiments, including four commercial carbamates, which were bendiocarb, carbofuran, propoxur and 8 new carbamates, which were PRC331, PRC337, PRC387, PRC388, PRC391, PRC407, PRC408 and PRC421 (Figure 2-1). The results showed that all carbamate insecticides inhibited all six AChE enzymes in a concentration-dependent manner, with varied potencies. Compared to commercial carbamates, novel carbamate insecticides showed moderate AChE inhibition capacity in all nontarget species (Table 3-2) and higher selectivity on An. gambiae over non-target species. In the commercial carbamate group, $\mathrm{IC}_{50}$ ranged from $9 \mathrm{nM}$ for D. magna with carbofuran to 2,094 $\mathrm{nM}$ for recombinant human with propoxur. Propoxur in all six species showed the highest $\mathrm{IC}_{50}$, ranging from $110 \mathrm{nM}$ for D. magna to 2,094 nM for recombinant humans, while carbofuran in all six species showed the lowest $\mathrm{IC}_{50}$, from $9 \mathrm{nM}$ for $D$. magna to $98 \mathrm{nM}$ for humans. In the novel carbamate group, the $\mathrm{IC}_{50}$ was overall numerically higher than that of the commercial carbamate group, which ranged from $58 \mathrm{nM}$ for D. magna with PRC337 to $388,800 \mathrm{nM}$ for hen brain homogenate with PRC421. PRC421 in all AChE of the six species showed the highest $\mathrm{IC}_{50}$, ranging from 3,308 $\mathrm{nM}$ for D. magna to $388,800 \mathrm{nM}$ for hen brain homogenate, while PRC331 in all six species showed the lowest $\mathrm{IC}_{50}$, from $86 \mathrm{nM}$ for D. magna to $373 \mathrm{nM}$ for hen brain homogenate (Table 3-2).

The $\mathrm{IC}_{50}$ data for An. gambiae were obtained from previous work in the Bloomquist laboratory, which were collected by Daniel Swale, James Mutunga, and Dawn Wong. Based on these data, a selectivity index ( $\mathrm{IC}_{50}$ of all six non-target species / $\mathrm{IC}_{50}$ of An. gambiae) was 
introduced (Table 3-2). The selectivity index in the commercial group remained low in all AChE sources, which ranged from 0.1 for $T$. californica with carbofuran and bendiocarb to 4.0 for humans with propoxur. This number in the novel carbamate insecticide groups varied from 0.3 for $T$. californica with PRC337 to 688 for hen brain homogenate with PRC421 (Table 3-2). 
Table 3-2. $\mathrm{IC}_{50}$ and selectivity index data obtained from 6 non-target species acetylcholinesterases using dilution with constant DMSO concentration for Ellman assay dilution.

\begin{tabular}{|c|c|c|c|c|c|c|c|c|c|}
\hline \multirow[b]{2}{*}{$\mathrm{IC}_{50}(\mathrm{nM})$} & \multicolumn{3}{|c|}{ Recombinant Mouse } & \multicolumn{3}{|c|}{ Recombinant Human } & \multicolumn{3}{|c|}{ Hen } \\
\hline & Mean & S.E.M & $\begin{array}{l}\text { Selectivity } \\
\text { index }\end{array}$ & Mean & S.E.M & $\begin{array}{l}\text { Selectivity } \\
\text { index }\end{array}$ & Mean & S.E.M & $\begin{array}{l}\text { Selectivity } \\
\text { index }\end{array}$ \\
\hline Bendiocarb & 214 & \pm 6.4 & 0.99 & 359 & \pm 16.2 & 1.67 & 107.7 & \pm 18.8 & 0.5 \\
\hline Carbofuran & 60 & \pm 3.7 & 0.7 & 97.9 & \pm 6.9 & 1.2 & 24.6 & \pm 2.2 & 0.3 \\
\hline Propoxur & 1,183 & \pm 73.7 & 2.2 & 2,094 & \pm 40.3 & 4 & 317.3 & \pm 73.3 & 0.6 \\
\hline PRC 331 & 171.6 & \pm 8.8 & 1.5 & 200.9 & \pm 18.7 & 1.8 & 373.2 & \pm 59.6 & 3.3 \\
\hline PRC 337 & 6,863 & \pm 109.3 & 40.6 & 10,920 & \pm 704.2 & 64.6 & 1,327 & \pm 233.5 & 7.9 \\
\hline PRC 387 & 2,241 & \pm 336.1 & 6 & 1,079 & \pm 165.5 & 2.9 & 6,765 & \pm 439.2 & 18.1 \\
\hline PRC 388 & 264.3 & \pm 70.2 & 6.1 & 294.3 & \pm 21.7 & 6.8 & 29,430 & $\pm 5,074$ & 684.4 \\
\hline PRC 391 & 15,830 & $\pm 3,017$ & 145.2 & 1,192 & $\pm 3,952$ & 10.9 & 26,580 & $\pm 6,589$ & 243.9 \\
\hline PRC 407 & 5,810 & $\pm 1,057$ & 84.2 & 12,070 & \pm 712.6 & 174.9 & 6,082 & \pm 212.3 & 88.1 \\
\hline RRC 408 & 22,010 & $\pm 4,781$ & 84 & 20,680 & $\pm 9,509$ & 78.9 & 58,760 & $\pm 9,674$ & 224.3 \\
\hline PRC 421 & 148,400 & $\pm 34,650$ & 406.6 & 247,400 & $\pm 106,800$ & 677.8 & 251,000 & $\pm 60,520$ & 687.7 \\
\hline
\end{tabular}


Table 3.2. continued

\begin{tabular}{|c|c|c|c|c|c|c|c|c|c|c|}
\hline \multirow[b]{2}{*}{$\mathrm{IC}_{50}(\mathrm{nM})$} & \multicolumn{3}{|c|}{ E. electricus } & \multicolumn{3}{|c|}{ T. californica } & \multicolumn{3}{|c|}{ D. magna } & \multirow{2}{*}{$\begin{array}{c}\text { An. gambiae } \\
\begin{array}{c}\text { Mean } \\
\text { (data from previous } \\
\text { study) }\end{array}\end{array}$} \\
\hline & Mean & S.E.M & $\begin{array}{l}\text { Selectivity } \\
\text { index }\end{array}$ & Mean & S.E.M & $\begin{array}{l}\text { Selectivity } \\
\text { index }\end{array}$ & Mean & S.E.M & $\begin{array}{l}\text { Selectivity } \\
\text { index }\end{array}$ & \\
\hline Bendiocarb & 80.6 & \pm 11.7 & 0.37 & 11.2 & \pm 2.2 & 0.05 & 126.3 & \pm 15.6 & 0.59 & 215.6 \\
\hline Carbofuran & 20.8 & \pm 2 & 0.3 & 9.1 & \pm 1.1 & 0.1 & 34.9 & \pm 1.9 & 0.4 & 80 \\
\hline Propoxur & 555.4 & \pm 156.6 & 1.1 & 110.8 & \pm 15.5 & 0.2 & 1,563 & \pm 144.5 & 3 & 527 \\
\hline PRC 331 & 113.8 & \pm 17.4 & 1 & 85.5 & \pm 13.2 & 0.8 & 167.3 & \pm 27 & 1.5 & 113 \\
\hline PRC 337 & 1,056 & \pm 58.5 & 6.2 & 58.3 & \pm 7.9 & 0.3 & 1,300 & \pm 83.3 & 7.7 & 169 \\
\hline PRC 387 & 335.9 & \pm 23.3 & 0.9 & 1,138 & \pm 152.7 & 3 & 515 & \pm 61.1 & 7.2 & 374 \\
\hline PRC 388 & 120.9 & \pm 11.7 & 2.8 & 1,612 & \pm 322 & 37.5 & 221.2 & \pm 39.6 & 5.1 & 43 \\
\hline PRC 391 & 3,735 & \pm 310.4 & 34.3 & 206.1 & \pm 39.7 & 1.9 & 3,705 & $\pm 1,023$ & 34 & 109 \\
\hline PRC 407 & 1,242 & \pm 40 & 18 & 229 & \pm 38.7 & 3.3 & 1,071 & \pm 192 & 15.5 & 69 \\
\hline RRC 408 & 1,241 & \pm 71.8 & 4.7 & 240.3 & \pm 19.9 & 0.9 & 585.2 & \pm 82.9 & 2.2 & 262 \\
\hline PRC 421 & 14,370 & $\pm 1,352$ & 39.4 & 3,308 & \pm 397.9 & 9.1 & 7,430 & \pm 698.5 & 20.4 & 365 \\
\hline
\end{tabular}

All data showed are in nM range. Data for each carbamate were repeated at least 4 times. All data were generated by using column statistics in GraphPad Prism $^{\mathrm{TM}}$ 5.0. Each data set was collected from experiments repeated at least three times.

(selectivity index $=\mathrm{IC}_{50}$ of all six non-target species $/ \mathrm{IC}_{50}$ of An. gambiae) 
Table 3-3. Comparison of the $\mathbf{R}^{2}$-value of the regression line between acetylcholinesterases of different animal species.

\begin{tabular}{|c|c|c|c|c|c|c|}
\hline $\mathbf{R}^{2}$ & $\begin{array}{c}\text { Recombinant } \\
\text { mouse }\end{array}$ & $\begin{array}{l}\text { Recombinant } \\
\text { human AChE }\end{array}$ & $\begin{array}{c}\text { Hen brain } \\
\text { homogenate }\end{array}$ & E. electricus & T. californica & D. magna \\
\hline $\begin{array}{c}\text { Recombinant } \\
\text { mouse }\end{array}$ & & 0.81 & 0.45 & 0.93 & $0.05 *$ & 0.81 \\
\hline $\begin{array}{l}\text { Recombinant } \\
\text { human AChE }\end{array}$ & 0.81 & & 0.31 & 0.70 & $0.05 *$ & 0.54 \\
\hline $\begin{array}{c}\text { Hen brain } \\
\text { homogenate }\end{array}$ & 0.45 & 0.31 & & $0.40 *$ & $0.55 *$ & $0.32 *$ \\
\hline E. electricus & 0.93 & 0.70 & $0.40 *$ & & 0.05 & 0.94 \\
\hline T. californica & $0.05 *$ & $0.05 *$ & $0.55 *$ & 0.05 & & 0.05 \\
\hline D. magna & 0.81 & 0.54 & $0.32 *$ & 0.94 & 0.05 & \\
\hline
\end{tabular}

$\mathrm{R}^{2}$ value was collected from GraphPad Prism ${ }^{\mathrm{TM}} 5.0$ as shown in Figure 3-2, following by a paired t-test, to determining any significant $\mathrm{IC}_{50}$ value differences among groups in GraphPad Prism ${ }^{\mathrm{TM}}$ 5.0. $P<0.05$ was considered to be significantly different and asterisk $(*)$ is used to indicate significance. 
As mentioned previously, highly correlated $\mathrm{IC}_{50}$ value of different carbamate insecticides indicated similarity between two enzymes. Here, the coefficient of determination $\left(\mathrm{R}^{2}\right)$ was used to determine the activity similarity between two enzymes. Correlations of AChE response pattern and level to the novel carbamates were then compared among six different $\mathrm{AChE}$ enzymes by using $\mathrm{IC}_{50}$ values obtained from the novel carbamates. The $\mathrm{R}^{2}$ values from the linear regression lines were shown in Table 3-3. The value of $\mathrm{R}^{2}$ varied from 0.05 to 0.94 , where E. electricus vs. D. magna had the highest $\mathrm{R}^{2}$ among all pairs. Among all test groups, only 7 of them showed $\mathrm{R}^{2}$ that were above 0.7, which were 0.94 for E. electricus vs. D. magna, 0.93 for E. electricus vs. recombinant mouse, 0.77 for recombinant human vs. recombinant mouse, and 0.70 for E. electricus vs. recombinant

human. T. californica had the consistently lowest $\mathrm{R}^{2}$ value when compared to the other species, except when vs. the hen sample (0.55). Paired t-tests showed that there were 5 pairs of enzymes that showed significantly different $\mathrm{IC}_{50}$ value, which were all related to $T$. californica and hen samples. These groups included T. californica vs. recombinant human, T. californica vs. recombinant mouse, T. californica vs. hen, hen vs. E. electricus, and hen vs. D. magna.

\subsection{Protein Sequence Alignment}

Five AChE protein sequences were obtained for alignment comparison (D. magna AChE protein sequence was not available from NCBI). The summary of the results are presented below (Table 3-4). 
Table 3-4. Summary of the multiple sequence alignment using 5 different animal species' acetylcholinesterases' protein sequence.

\begin{tabular}{|c|c|c|c|c|c|}
\hline $\begin{array}{l}\text { Name of } \\
\text { sequence }\end{array}$ & length & W & $\begin{array}{l}\text { Name of } \\
\text { sequence }\end{array}$ & length & Score \\
\hline Mus & 614 & & Homo & 614 & 88 \\
\hline Torpedo & 596 & & Electrophorus & 633 & 67 \\
\hline Mus & 614 & & Electrophorus & 633 & 60 \\
\hline Hoто & 614 & & Gallus & 767 & 60 \\
\hline Mus & 614 & & Gallus & 767 & 59 \\
\hline Homo & 614 & & Electrophorus & 633 & 59 \\
\hline Mus & 614 & & Torpedo & 596 & 58 \\
\hline Homo & 614 & & Torpedo & 596 & 57 \\
\hline Gallus & 767 & & Electrophorus & 633 & 55 \\
\hline Gallus & 767 & & Torpedo & 596 & 54 \\
\hline
\end{tabular}

Length number indicates the number of amino-acids that formed the AChE protein precursor. The score of the alignment number represents the similarity between AChE from different species. The higher the score, the greater genetic similarity they share. All sequence information was obtained from NCBI database (The National Center for Biotechnology Information, http://www.ncbi.nlm.nih.gov/). Mus = mouse, Homo = human, Torpedo $=T$. californica, Electrophorus $=$ E. electricus, Gallus $=$ hen

For most of the species, AChE precursors were around 610 amino acids (AAs) (Table 34). The longest $\mathrm{AChE}$ precursor belonged to hen, which was $767 \mathrm{AAs}$, while the shortest one was T. californica, which was 596 AAs. Human and mouse AChE had the same length which was 614 AAs. At the very right column of Table 4, the scores of pairwise alignment were listed and sorted in a high to low order. I found that highest number was obtained between mouse vs. human, while the lowest number was between hen vs. T. californica. Based on the sequence of the AChE enzyme, a cladogram was obtained and shown below (Figure 3-4): 


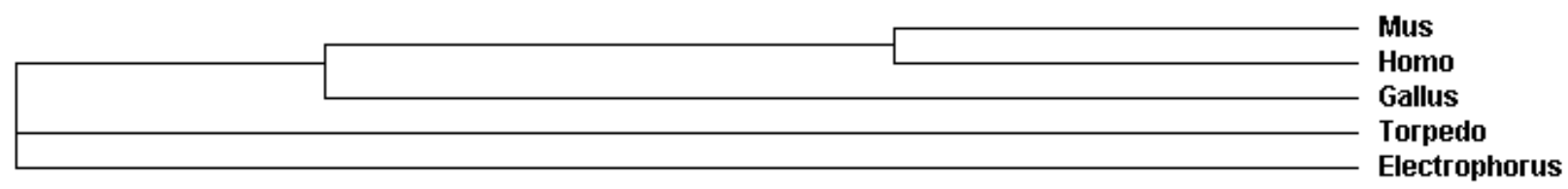

Figure 3-4. Cladogram comparing the relationships between acetylcholinesterases from five animals. Results summary and phylogram tree were automatically generated by ClustalW2EMBL-EBI (The European Molecular Biology Laboratory - European Bioinformatics Institute, http://www.ebi.ac.uk/Tools/msa/clustalw2/). Mus = mouse, Homo= human, Torpedo $=$ T. californica, Electrophorus $=$ E. electricus, and Gallus $=$ hen.

In Figure 3-4, the cladogram showed that $\mathrm{AChE}$ from two mammalian animals, mouse and human, were closely related. Hens were closer to these mammals than the two fish.

\subsection{NTE Inhibition Testing by NTE Assay}

A measurement of NTE activity inhibition was carried out on hen's brain homogenate from the lab of Dr. Ehrich Marion. For each single experiment, I used the standard NTE positive control diisopropylphosphorofluoridate (DFP). As illustrated in Table 3-5, DFP (0.5 uM) produced a decreased level of NTE activity, which was $20 \%$ of initial NTE activity $(P<0.0001, \mathrm{n}=8)$. Then all carbamate insecticides were tested under the same experimental conditions. The data are shown in the Table 3-5. For commercial carbamate insecticides, compared to control group, significant NTE inhibition was observed at $1 \mathrm{mM}$ bendiocarb $(\mathrm{P}=0.0037, \mathrm{n}=8)$, where the remaining NTE activity was $76 \%$ of control. The rest of the commercial carbamate insecticides at $1 \mathrm{mM}$ did not show significant NTE inhibition compared to control NTE reactivity. The remaining NTE activity varied from 93\% for PRC337 to 116\% for PRC421 (Table 3-5). 
Table 3-5. Comparison of neurotoxic esterase assay results by using hen brain homogenate.

\begin{tabular}{ccc}
\hline \hline Hen Sample & \% of control & Std. Deviation \\
\hline \hline Control & 100.00 & $\pm 0 \%$ \\
DFP $(0.0005 \mathrm{mM})$ & $19.76 *$ & $\pm 4.3 \%$ \\
bendiocarb $(1 \mathrm{mM})$ & $76.4 *$ & $\pm 14 \%$ \\
carbofuran $(1 \mathrm{mM})$ & 100.5 & $\pm 9.6 \%$ \\
propoxur $(1 \mathrm{mM})$ & 97.17 & $\pm 11.2 \%$ \\
PRC331 $(1 \mathrm{mM})$ & 101.1 & $\pm 11.8 \%$ \\
PRC337 $(1 \mathrm{mM})$ & 93.32 & $\pm 12.8 \%$ \\
PRC387 $(1 \mathrm{mM})$ & 111.5 & $\pm 17.6 \%$ \\
PRC388 $(1 \mathrm{mM})$ & 98.59 & $\pm 11.7 \%$ \\
PRC391 $(1 \mathrm{mM})$ & 97.41 & $\pm 12.7 \%$ \\
PRC407 $(1 \mathrm{mM})$ & 101.5 & $\pm 12.8 \%$ \\
PRC408 $(1 \mathrm{mM})$ & 110.9 & $\pm 16.9 \%$ \\
PRC421 $(1 \mathrm{mM})$ & 116.4 & $\pm 26.1 \%$ \\
\hline \hline
\end{tabular}

Amount of remaining NTE activity of hen brain homogenate tested on both commercial and novel carbamate insecticides. Each result was the average of experiments repeated at least 3 times. The one-way ANOVA with Dunnett's post test was conducted to detect difference from control in GraphPad Prism ${ }^{\mathrm{TM}}$ 5.0. Asterisk $(*)$ represents significant difference. 


\subsection{In vivo D. magna Aquatic Toxicity Bioassay}

In this set of experiments, concentrations as high as $10^{-5} \mathrm{M}$ led to $100 \%$ mortality in $D$. magna for all carbamate insecticides. Bendiocarb was used as a representative of commercial carbamates. The sigmoidal curve analysis showed that its $\mathrm{LC}_{50}$ (median lethal concentration) was $611 \mathrm{nM}$ (Table 3-6). In the novel carbamate group, 7 of them presented $\mathrm{LC}_{50}$ values at about the same potency as bendiocarb, which were PRC337, PRC 387, PRC388, PRC391, PRC407, PRC408 and PRC421. Among these seven novel carbamates, PRC407 and PRC408 had the lowest $\mathrm{LC}_{50}$, while PRC421 had the highest $\mathrm{LC}_{50}$. PRC331 was the only novel carbamate that presented significantly lowered (3.5-fold) $\mathrm{LC}_{50}$ value compared to bendiocarb $(P=0.0349)$.

Table 3-6. In vitro toxicity aquatic bioassay results by using $D$. magna.

\begin{tabular}{ccc}
\hline \hline Compound & LC $_{\mathbf{5 0}}(\mathbf{n M})$ & S.E.M \\
\cline { 2 - 3 } bendiocarb & 611 & \pm 179 \\
PRC331 & $172 *$ & \pm 28 \\
PRC337 & 439 & \pm 236 \\
PRC387 & 1109 & \pm 549 \\
PRC388 & 258 & \pm 130 \\
PRC391 & 755 & \pm 243 \\
PRC407 & 225 & \pm 56 \\
PRC408 & 225 & \pm 62 \\
PRC421 & 834 & \pm 63 \\
\hline
\end{tabular}

Each data number was the average of experiment results repeated at least for 3 times. One-way ANOVA with Dunnett's post test was conducted to detect difference from the standard in GraphPad Prism ${ }^{\mathrm{TM}} 5.0$. Asterisk $(*)$ represents significant difference between bendiocarb and experimental compound. 


\section{Chapter 4 Discussion}

Initial studies established experimental conditions to be used throughout this research. Data from these experiments using DWOCD (Table 3-1, Figure 3-1) were similar to previous studies. It is reported that the $\mathrm{IC}_{50}$ for aldicarb was $2543 \mathrm{nM}$ (postnatal day 4 rat, incubation time 30min), for carbofuran was $150 \mathrm{nM}$ (8 weeks old rat plasma cholinesterase, incubation time 1 min) and for carbaryl was $1758 \mathrm{nM}$ (postnatal day 4 rat, incubation time 30min) (Lyaniwura 1989; Mortensena et al. 1998). Thus, results from rat were close to the mouse $\mathrm{IC}_{50}$ values that I measured. As expected, there was also a close correlation between recombinant murine AChE and that found in brain cortex homogenates, which suggests that the recombinant enzyme faithfully reflects that of the native, at least from the perspective of carbamate action.

Subsequent studies explored the effects of DMSO as a solvent compound, for which it is widely used in both chemical and biological research (Tjernberg et al. 2006). Its chemical properties allow it to be soluble in both organic and non-organic media because of the combination of one polar domain and two non-polar domains (Santos et al. 2003). As a hydrogen-bond disruptor (Santos et al. 1997), DMSO has been shown to affect normal cell physiological process, such as cell cycle adjustment, differentiation and apoptosis (Parkin et al. 1997). When the commercial carbamates were evaluated, all data fitted well to a sigmoidal curve and I obtained reasonable $\mathrm{R}^{2}$ and Hill slope values. However, when applying the same procedure to the novel carbamates, the poor solubility prevented them from forming a welldistributed suspension. A film was formed on the top of the sodium-phosphate buffer when I transferred $100 \mathrm{ul} 0.1 \mathrm{M}$ stock solution into the aliquot. Even extensive vortexing would not 
distribute the compound into the buffer. Subsequent dilution further amplified this error, giving spurious results.

Then I switched the dilution method from DW/OCD to DWCD. The results showed that the commercial carbamates had a low $\mathrm{IC}_{50}$ and potent inhibition capacity on $\mathrm{AChE}$, in vitro, on non-target animal species. In addition, I showed that bendiocarb, carbofuran, and propoxur were poorly selective on $\mathrm{AChE}$ of non-target species. As mentioned before, the potent $\mathrm{AChE}$ inhibition capacity and low selectivity of commercial carbamates have long been a serious safety issue for mammals, livestock, and the aquatic environment, especially in areas relying on carbamates for malaria control and agriculture. For the novel carbamates, AgAChE inhibition capacity was comparable to that of the commercial carbamates (Swale 2009; works from Dawn Wong and James Mutunga). However, their selectivity indices were much higher than the commercial carbamates, indicating less AChE inhibition potency on non-target species. Thus, this set of data suggests a more prominent safety property of the novel carbamates. Because of the complexity of pharmacokinetic processes, in vitro bioassay cannot give an exact prediction of in vivo toxicity. Thus, in future work, in vivo bioassay using small vertebrate animals should be conducted. I would expect to see less acute lethality on those non-target species in vivo, which would confirm the safety properties of the novel carbamates obtained, in vitro.

This study also offered me the insight into the structure-activity relation of carbamates and the preferred structures for different AChEs. The branched chain on the phenyl ring affects the AChE inhibition potency of carbamates greatly (Kuhr and Dorough 1976). Generally speaking, alkyl substituents at the meta- position make a carbamate a more potent enzyme inhibitor than at the ortho- position (Kuhr and Dorough 1976). This statement is supported by my results, since the ortho-substituted carbamates on the phenyl ring have a higher $\mathrm{IC}_{50}$ than 
meta- position carbamates. However, meta-substituted carbamates are not as potent AChE inhibitors as carbofuran or bendiocarb (essentially benzofurans with 1 [carbofuran] or 2 [bendiocarb] oxygens, the latter known as dioxolane). The benzofuran/dioxolane materials are also the least selective, probably because their structures are more rigid, thereby optimizing interaction with highly conserved substructures of the CAS across species. Conversely, they lack the side chain flexibility that might accommodate various substructures and protein conformations of different species, and contribute to selectivity. In conclusion, the benzofuran and similar structures are not good options for selective carbamate insecticide design.

In my study, I used propoxur, PRC 337, PRC391, PRC407, PRC408 and PRC421, which are ortho-substituted carbamates (ortho- position side chain on the phenyl ring). Propoxur and PRC421 are two ortho-substituted carbamates that use oxygen to link the phenyl ring and the side chain while PRC337, PRC391, PRC407 and PRC408 use the sulfur (Table 2-1). For all non-target species, propoxur usually has the lowest $\mathrm{IC}_{50}$ while the PRC421 had the greatest (Table 3-2). As mentioned above, increasing side chain length from 1 carbon to 3 carbons could enhance the anticholinesterase capacity, but decreases it when the side chain is longer than 4 carbons (Kuhr and Dorough 1976). Comparing the chemical structures, PRC421 has a longer (1 oxygen and 4 carbons side chain backbone) and more branched side chain than propoxur (1 oxygen and 2 carbons side chain backbone). The co-effect of these two factors makes PRC421 have a much higher $\mathrm{IC}_{50}$ value than propoxur throughout all six species. Although PRC421 also decreased $A g \mathrm{AChE}$ inhibition potency, the severe effect on non-target AChE inhibition potency increased the selectivity index throughout all species tested. This finding offers a promising structure for selective carbamate insecticide design. 
In the novel carbamate group, there are three meta-substituted carbamates, which are PRC331, PRC387 and PRC388 (Table 2-1). PRC331 is the only compound that uses carbon to link the side chain and phenyl ring. Compared to the other two carbamates, its $\mathrm{IC}_{50}$ value was also the smallest throughout all six species' AChE (Table 3-1). However, when the carbon connecting the phenyl ring and alkyl side chains is replaced with silicon (PRC387), the $\mathrm{IC}_{50}$ value of PRC387 increased from 2.95-fold for E. electricus (from $113.8 \mathrm{nM}$ to $335.9 \mathrm{nM}$ ) to 18 fold for hen (from $373.2 \mathrm{nM}$ to $6,765 \mathrm{nM}$ ). Apparently, the slightly longer carbon-silicon bond, which is $1.89 \AA$ compared to $1.54 \AA$ for carbon-carbon bond (Allen et al. 1987) can induce an apparent $\mathrm{IC}_{50}$ shift. This finding suggests a narrow site in the all non-target species' $\mathrm{AChE}$, which fits carbon-carbon bond better than carbon-silicon bond. Comparing one side chain that is ethyl (PRC387) to methyl (PRC388), increased the AChE inhibition potency in most species, but not hen (changed from $6,765 \mathrm{nM}$ to $29,430 \mathrm{nM}$ ) and T. californica (changed from 1,138 $\mathrm{nM}$ to $1,612 \mathrm{nM})$. For the hen and T. californica, the 4.3-fold and 1.4-fold $\mathrm{IC}_{50}$ value increase suggest that the ethyl side chain is too long. For the rest of the non-target species, ethyl groups fit better in this position on their $\mathrm{AChE}$. However, potency on $\mathrm{AgAChE}$ showed an even greater potency increase from this structural change (8.7-fold potency increase), which had an overall effect of prominently increasing the selectivity index across all non-target species.

AChE structure and sensitivity to inhibitors varies between different species. The two mammalian AChEs, which were recombinant human $\mathrm{AChE}$ and recombinant mouse $\mathrm{AChE}$, appeared to have a similar sensitivity pattern and level to the novel carbamates (Table 3-3) and highly similar protein sequence alignment (Table 3-4). In addition, the cladogram tree showed they were evolutionarily more closed to each other than any other tested species. Hen AChE was genetically and evolutionarily not very close to the human and mouse, as indicated by the 
moderate score from the AChE protein sequence alignment and far taxa position on the cladogram. My experimental data verified this relationship by showing a different sensitivity pattern to the novel carbamates $\left(\mathrm{R}^{2}<0.45\right)$ between the hen and other two mammalian species. However, based on my findings, hen AChE was more closely related to mammalian AChE than that of the aquatic species. In aquatic groups, E. electricus vs. D. magna had the highest $\mathrm{R}^{2}(0.94)$ and similar carbamate sensitivity levels. Thus, although the AChE protein sequence of $D$. magna is currently not available online, it would be reasonable to hypothesize that AChE of $D$. magna would be more genetically and evolutionarily close to that of E. electricus. It was very surprising to see that E. electricus and T. californica had a different AChE sensitivity pattern to the novel carbamates $\left(\mathrm{R}^{2}=0.05\right)$. According the data, they shared the second highest score of AChE protein sequence alignment (66) and similar AChE sensitivity level to the novel carbamates. Apparently, their structures differ in accommodating novel carbamate side chains in a way not obvious from their protein sequence.

NTE inhibitors are categorized into two groups, which are neuropathic and nonneuropathic NTE inhibitors (Glynn 2006; Moretto and Lotti 2006). Aging only occurs in the NTE-neuropathic organophosphate inhibitor complex, which causes OPIDN (Glynn 2006). However, because of the finding that some carbamates are capable of inducing polyneuropathy at high doses (Lotti and Moretto 2006; Randall et al. 1997), the safety testing for carbamates now also includes NTE toxicity testing. In my study, I used hen brain homogenate to test the NTE inhibition on both commercial and novel carbamate insecticides. The results showed that not all commercial carbamate insecticides but all novel commercial carbamate insecticides have no adverse effect on NTE. The exception was bendiocarb, which at $1 \mathrm{mM}$ could inhibit NTE in vitro. Because there is no literature demonstrating whether bendiocarb can cause OPIDN, it will 
be very interesting to take a further look at, not only bendiocarb, but other commercial carbamates. Overall, this set of experiments suggested that the novel carbamates are unlikely to cause delayed neuropathy via inhibition of NTE. In future work, in vivo bioassay using hen should be conducted to confirm this speculation. The safety features of the novel carbamates will be reconfirmed if they are not OPIDN-inducing in this model.

D. magna is recommended by the Food and Drug Administration (FDA) and Office of Pollution Prevention and Toxics (OPPT) as a standard animal model for acute or chronic toxicity testing (Versteeg et al. 1997), and has been regarded as one of the most reliable indicators for exposing potential environmental problems (Dodson and Hanazato 1995). Thus, I used $D$. magna as an in vivo non-target animal model. In addition, because bendiocarb has been well studied in aquatic toxicology (PAN Pesticides Database 2000), bendiocarb was selected as representative of the commercial carbamates. According to the literature, the 24-hour acute toxicity for bendiocarb is $1.4 \mathrm{uM}$ in in vivo aquatic assay using D. magna (PAN Pesticides Database 2005). As compared to the $\mathrm{LC}_{50}$ data $(0.61 \mathrm{uM}) \mathrm{I}$ obtained, it is convincing that my bioassay system is accurate. PRC 331 is the only novel carbamate that showed significantly lowered $\mathrm{LC}_{50}$ compared to bendiocarb, with the rest of the novel carbamates having similar killing potency as bendiocarb. Bendiocarb has been categorized as a carbamate with moderate to high toxicity to aquatic animal species, including both the vertebrate (fish) and the invertebrates (shrimp, crabs, and insects) (PAN Pesticides Database 2000; Wright et al. 1981). In this case, because of its more potent aquatic toxicity to non-target species than the existing commercial carbamates (bendiocarb), PRC331 is not a good option for An. gambiae larva control for aquatic application. However, since it is envisioned to use this compound in bednets or as IRS, I think it is still a good candidate for An. gambiae control in other life stages, such as adult stage. For the 
rest of the novel carbamates, which are PRC337, PRC387, PRC388, PRC391, PRC407, PRC408 and PRC421, further An. gambiae larvae in vivo bioassay will need to be conducted. If the data could prove that they have a lower $\mathrm{LC}_{50}$ and higher killing capacity on An. gambiae larvae compared to the commercial carbamates, they might be developed as optimum candidates for both An. gambiae adult and larva control.

\section{Chapter 5 Conclusions}

For malaria control, the carbamate insecticides presently in use (propoxur and bendiocarb) are mostly non-selective, and inhibit both target (mosquito) AChE and non-target (human and other mammalian) AChE. Because these non-selective carbamate insecticides have been used in malaria endemic areas, safety concerns are raised because of intoxication of humans and other non-target species. Thus, it is reasonable to develop some selective carbamate insecticides, which would selectively inhibit target AChE but not the others. Overall, I obtained convincing results that, in vitro, the novel carbamate insecticides have improved properties compared to the WHO Pesticide Evaluation Scheme (WHOPES) standards propoxur and bendiocarb.

In this study, I first showed the accuracy of my testing system by evaluating nine commercial carbamates on three vertebrate AChE enzyme sources in the Ellman assay, which used a DW/OCD method for preparation. However, because DW/OCD was not shown to be reliable for the novel carbamates, I switched to DWCD method instead and obtained good results.

After selecting the optimum preparation method, I started collecting $\mathrm{IC}_{50}$ values and found selectivity differences between the commercial carbamates and the novel carbamates. Compared to 
the commercial ones, I found that the novel carbamates had a higher selectivity on target AChE species (An. gambiae). In addition, NTE assay was conducted and the data showed that the novel carbamates were not toxic to NTE at $1 \mathrm{mM}$ concentration. These two sets of experiment provided information that the novel carbamates have a strong inhibition and high selectivity for AChE of target species and should not be neuropathy-inducing.

AChE activity and protein sequence were compared throughout all non-target species. I found that mouse and human AChE were highly similar in sensitivity pattern and level to the novel carbamates, AChE protein sequence, and evolutionary relationship. For the two aquatic fishes, although they also have a moderate alignment score and similar AChE activity, they had a different patterns of response to the novel carbamates. Hen has a higher alignment score with the two mammalian organisms than that of the aquatic animals. However, it had a different reaction pattern to the novel carbamates compared to the mouse and human. Thus, I conclude that mouse and human AChE are most similar to each other both genetically, evolutionarily, and functionally. Hen $\mathrm{AChE}$ is genetically more close to the mammalian but has a unique AChE activity pattern to the novel carbamates.

For in vivo aquatic toxicology bioassay using D. magna, PRC331 showed a significantly lowered $\mathrm{LC}_{50}$ compared to bendiocarb, which suggested that it is not a good candidate for $A n$. gambiae larvae control. The safety features of PRC337, PRC387, PRC388, PRC391, PRC407, PRC408 and PRC421 allow them to be considered as options for both An. gambiae larvae and adult control.

For future study, in vivo bioassay using An. gambiae and small vertebrate animals should be conducted to confirm the safety property of the novel carbamates in real conditions. All novel carbamates should also be tested in aquatic toxicology assay on An. gambiae larvae stages. Finally, 
the contact, fumigant, and repellent bioassay should also be done on adult An. gambiae with all novel carbamates. 


\section{Chapter 6 References}

Abbott, WS (1925). A method of computing the effectiveness of insecticide. J. Econ. Entomol. 18: 265267.

Ahdaha, SM; Monroe, RJ; Guthrie, FE (1981). Absorption and distribution of intubated insecticides in fasted mice. Pestic. Biochem. Phys. 16(1): 38-46.

Akogbéto, MC; Padonou, GG; Gbénou, D; Irish, S; Yadouleton, A (2010). Bendiocarb, a potential alternative against pyrethroid resistant Anopheles gambiae in Benin, West Africa. Malar. J. 9: 204.

Aldridge, WN; Reiner, E (1972). Enzyme inhibitors as substrates: interactions of esterases with esters of organophosphorus and carbamic acids. Amsterdam, North-Holland Pub. Co.: 328

Allen, FH; Kennard, O; Watson, DG (1987). Tables of bond lengths determined by X-ray and neutron diffraction. Part I. Bond lengths in organic compounds. J. Chem. Soc. Perkin Trans. II. 7(194): S1-S19.

Ameno, K; Lee, SK; In, SW; Yang, JY; Yoo, YC; Ameno, S; Kubota, T; Kinoshita, H; Ijiri, I (2001). Blood carbofuran concentrations in suicidal ingestion cases. Forensic Sci. Int. 116(1): 59-61.

Anonymous, United Nations Children's Fund (2008). "State of the world Children". Child. Survival., UNICF.

Baban, NK; Nunley, DL; Borges, AS Jr; Roy, TM. (1998). Human sequelae of severe carbamate poisoning. Tenn. Med. 91(3): 103-106.

Bardin, PG; van Eeden, SF; Moolman, JA; Foden, AP; Joubert, JR (1994). Organophosphate and carbamate poisoning. Arch. Intern Med. 154(13): 1433-1441.

Barnat, S; Boisset, M; Casse, F; Catteau, M; Lecerf, JM; Veschambre, D; Periquet, A (2010). Pesticide residues intake of French adults under increased consumption of fresh fruits and vegetables--a theoretical study. J. Environ. Sci. Health. B. 45(2): 102-107.

Baron, RL (1991). Carbamate Insecticides. Handbook of Pesticide Toxicology. New York, Eds. Academic Press: 1087-1211.

Beier, JC; Perkins, PV; Onyango, FK; Gargan, TP; Oster, CN; Whitmire, RE; Koech, DK; Roberts, CR (1990). Characterization of malaria transmission by Anopheles (Diptera: Culicidae) in western Kenya in preparation for malaria vaccine trials. J. Med. Entomol. 27: 570-577.

Bhattarai, A; Ali, AS; Kachur, SP; Mårtensson, A; Abbas, AK; Khatib, R; Al-Mafazy, AW; Ramsan, M; Rotllant, G; Gerstenmaier, JF; Molteni, F; Abdulla, S; Montgomery, SM; Kaneko, A; Björkman, A (2007). Impact of artemisinin-based combination therapy and insecticide-treated nets on malaria burden in Zanzibar. PLoS. Med. 4(11): e309.

Boon, PE; Van der Voet, H; Van Raaij, MT; Van Klaveren, JD (2008). Cumulative risk assessment of the exposure to organophosphorus and carbamate insecticides in the Dutch diet. Food. Chem. Toxicol. 46(9): 3090-3098. 
Bouldin, WT; Cavanagh, JB (1979b). Organophosphorous neuropathy. Am. J. Path. 94: 253-261.

Bourguet, D; Roig, A; Toutant, JP; Arpagaus, M (1997). Analysis of molecular forms and pharmacological properties of acetylcholinesterase in several mosquito species. Neurochem. Int. 31(1): 65-72.

Bourne, Y; Taylor, P; Bougis, PE; Marchot, P (1999). Crystal structure of mouse acetylcholinesterase: a peripheral site-occluding loop in a tetrameric assembly. J. Biol. Chem. 274(5): 2963-2970.

Bourne, Y; Taylor, P; Marchot, P (1995). Acetylcholinesterase inhibition by fasciculin: crystal structure of the complex. Cell 83(3): 503-512.

Bucht, G; Häggström, B; Radić, Z; Osterman, A; Hjalmarsson, K (1994). Residues important for folding and dimerisation of recombinant Torpedo californica acetylcholinesterase. Biochim. Biophys. Acta. 1209(2): 265-273.

Callec, JJ (1985). Synaptic transmission in the central nervous system. Comprehensive Insect Physiology, Biochemistry \& Pharmacology. Kerkut, GA \& Gibert, LI. Pergamon Press: 139-179.

Calli, CL; Marinovich, M (1987). Dermal toxicity of pesticides. Toxicology of Pesticides: Experimental, Clinical, and Regulatory Perspectives. Costa, LG; Galli, CL; Murphy, SD. New York, Springer-Verlag: 147-169.

Carboni, D; Ehrich, M; Dyer, K; Jortner, BS (1992). Comparative evolution of mipafox-induced delayed neuropathy in rats and hens. Neurotoxicology. 14(4): 723-733.

Casida, JE; Quistad, GB (2004). Organophosphate toxicology: safety aspects of non-acetylcholinesterase secondary targets. Chem. Res. Toxicol. 17(8): 983-998.

Chen, KC; Dorough, HW (1979). Glutathione and mercapturic acid conjugations in the metabolism of naphthalene and 1-naphthyl N-methylcarbamate (carbaryl). Drug. Chem. Toxicol. 2(4): 331-354.

Clothier, B; Johnson, MK (1980). Reactivation and aging of neurotoxic esterase inhibited by a variety of organophosphorus esters. Biochem. J. 185(3): 739-747.

Conteh, L; Sharp, BL; Streat, E; Barreto, A; Konar, S (2004). The cost and cost-effectiveness of malaria vector control by residual insecticide house-spraying in southern Mozambique: a rural and urban analysis. Trop. Med. Int. Health. 9(1): 125-132.

Corbel, V; Hougard, JM; N'Guessan, R; Chandre, F (2003). Evidence for selection of insecticide resistance due to insensitive acetylcholinesterase by carbamate-treated nets in Anopheles gambiae s.s. (Diptera: Culicidae) from Côte d'Ivoire. J. Med. Entomol. 40(6): 985-988.

Croft, AM; Whitehouse, DP; Cook, GC; Beer, MD (2002). Safety evaluation of the drugs available to prevent malaria. Expert. Opin. Drug. Saf. 1(1): 19-27.

Davis, CS; Johnson, MK; Richardson, RJ (1985). Organophosphorus compounds. Neurotoxicity of Industrial and Commercial Chemicals. O'Dorough, J. Boca Raton, Florida, CRC Press. II: 1-23. 
Dawson, RM (1995). Oxime effects on the rate constants of carbamylation and decarbamylation of acetylcholinesterase for pyridostigmine, physostigmine and insecticidal carbamates. Neurochem. Int. 26(6): 643-665.

Djènontin, A; Chabi, J; Baldet, T; Irish, S; Pennetier, C; Hougard, JM; Corbel, V; Akogbéto, M; Chandre, F (2009). Managing insecticide resistance in malaria vectors by combining carbamate-treated plastic wall sheeting and pyrethroid-treated bed nets. Malar. J. 8: 233.

Djènontin, A; Chandre, F; Dabiré, KR; Chabi, J; N'guessan, R; Baldet, T; Akogbéto, M; Corbel, V (2010). Indoor use of plastic sheeting impregnated with carbamate combined with long-lasting insecticidal mosquito nets for the control of pyrethroid-resistant malaria vectors. Am. J. Trop. Med. Hyg. 83(2): 266270.

Dodson, SI; Hanazato, T (1995). Commentary on effects of anthropogenic and natural organic-chemicals on development, swimming behavior and reproduction of Daphnia, a key member of aquatic ecosystems. Environ. Health. Perspect. 103(4): 7-11.

Dondorp, AM; François Nosten, F; Yi, P; Das, D; Phyo, AP; Tarning, J; Lwin, KM; Ariey, F; Hanpithakpong, W; Lee, SJ; Ringwald, P; Silamut, K; Imwong, M; Chotivanich, K; Lim, P; Herdman, T; An, SS; Yeung, S; Singhasivanon, P; Day, NP; Lindegardh, N; Socheat, D;White, NJ (2009). Artemisinin resistance in Plasmodium falciparum malaria. N. Engl. J. Med. 361(5): 455-467.

Dorough, HW (1968). Metabolism of Furadan (NIA-10242) in rats and houseflies. J. Agr. Food. Chem. 16: 319-325.

Dorough, HW (1979). Metabolism of insecticides by conjugation mechanisms. Pharmacol. Ther. 4(2): 433-471.

Dorough, HW; Leeling, NC; Casida, JE (1963). Nonhydrolytic pathway in metabolism of Nmethylcarbamate insecticides. Science 140(3563): 170-171.

Drakontides, AB; Baker, T; Riker, WF Jr. (1982). A morphological study of the effect of glucocorticoid treatment on delayed organophosphorus neuropathy. Neurotoxicology. 3(4): 165-177.

Dudek, BR; Barth, L; Gephart, L; Huggins, J; Richardson, RJ (1979). Correlation of brain and lymphocyte neurotoxic esterase inhibition in the adult hen following dosing with neurotoxic compounds. Toxicol. App. Pharmacol. 48: A198.

Dudek, RB; Richardson, RJ (1982). Evidence for the existence of neurotoxic esterase in neural and lymphatic tissue of the adult hen. Biochem. Pharmacol. 31: 1117-1121.

Ecobichon, DJ (2001). Carbamate insecticides. Handbook of Pesticide Toxicology. Krieger, R. Academic Press: $1087-1106$.

Ekstrom, F; Akfur, C; Tunemalm, AK; Lundberg, S (2006). Structural changes of Phenylalanine 338 and Histidine 447 revealed by the crystal structures of tabun-inhibited murine acetylcholinesterase. Biochemistry 45(1): 74-81.

Ellman, GL; Courtney, KD; Anders, V Jr; Feather-Stone, RM (1961). A new and rapid colorimetric determination of acetylcholinesterase activity. Biochem. Pharmacol. 7: 88-95. 
Flacke, W (1973). Treatment of myasthenia gravis. N. Engl. J. Med. 288(1):27-31.

Foran, JA; Germuska, PJ; Delfino, JJ (1985). Acute toxicity of aldicarb, aldicarb sulfoxide, and aldicarb sulfone to Daphnia laevis. Bull. Environ. Contam. Toxicol. 35(4): 546-550.

Forist, AA; Judy, RW (1971). Comparative pharmacokinetics of chlorphenesin carbamate and methocarbamol in man. J. Pharm. Sci. 60(11): 1686-1688.

Fukuto, TR (1990). Mechanism of action of organophosphorus and carbamate insecticides. Environ. Health Perspect. 87: 245-254.

Gillette, JR; Conney, AC; Cosmides, GJ; Estabrook, RW; Fouts, JR; Mannering, GJ (1969). Microsomes \& Drug Oxidation. New York, Academic Press. 206-247.

Glynn, P; Johnson, MK (2001) Neuropathy target esterase. Handbook of Pesticide Toxicology. Krieger, R. Academic Press. 953-966.

Glynn, P (2005). Neuropathy target esterase and phospholipid deacylation. Biochim. Biophys. Acta. 1736(2): 87-93.

Glynn, P (2006). A mechanism for organophosphate-induced delayed neuropathy. Toxicol. Lett. 162(1): 94-97.

Goldfain, E (1930). Jamaica ginger multiple neuritis. J. Okla. State. Med. Assoc. 23: 191-192.

Gupta, RC (2006). Toxicology of Organophosphate and Carbamate Compounds. San Diego, Elsevier Academic Press. 271-495

Hall, RC; Harris, DE (1979). Direct gas chromatographic determination of carbamate pesticides using carbowax 20M-modified supports and the electrolytic conductivity detector. J. Chromatogr. 169: 245-259.

Harel, M; Kryger, H; Rosenberry, T; Mallender, W; Lewis, T; Fletcher, R; Guss, J; Silman, I; Sussman, J (2000). Three-dimensional structures of Drosophila melanogaster acetylcholinesterase and of its complexes with two potent inhibitors. Protein. Sci. 9(6): 1063-1072.

Hodgson, E; Goldstein, JA (2001). Metabolism of toxicants: Phase I reactions and pharmacogenetics. Introduction to Biochemical Toxicology. Hodgson, E \& Smart RC. New York, Wiley: 67-113.

Hodgson, E; Rose, RL (2004). Metabolism of toxicants. A Textbook of Modern Toxicology. Hodgson, E. New Jersey, John Wiley \& Sons, Inc.: 111-148.

Ioannides, C (2002). Enzyme systems that metabolize drugs and other xenobiotics. Chichester, UK, John Wiley \& Sons, Ltd.: 353-422.

Jakoby, WB; Ziegler, DM (1990). The enzymes of detoxication. J. Biol. Chem. 265(34): 20715-20718.

Jamshidzadeh, A; Niknahad, H; Kashafi, H (2007). Cytotoxicity of chloroquine in isolated rat hepatocytes. J. Appl. Toxicol. 27(4): 322-326.

Johansson, B (1992). A review of the pharmacokinetics and pharmacodynamics of disulfiram and its metabolites. Acta. Psychiatr. Scand. Suppl. 369: 15-26. 
Johnson, MK (1969). The delayed neurotoxic effect of some organophosphorus compounds. Biochem. J. 114(4): 711-717.

Johnson, MK (1970). Organophosphorus and other inhibitors of brain "neurotoxic esterase" and the development of delayed neurotoxicity in hens. Biochem. J. 120(3): 523-531.

Johnson, MK (1974). The primary biochemical lesion leading to the delayed neurotoxic effects of some organophosphorus esters. J. Neurochem. 23(4): 785-789.

Johnson, MK (1975). The delayed neuropathy caused by some organophosphorusesters: mechanism and challenge. CRC Crit. Rev. Toxicol. 3(3): 289-316.

Johnson, MK (1977). Improved assay of neurotoxic esterase for screening organophosphates for delayed neurotoxicity potential. Arch. Toxicol. 37(2): 113-115.

Johnson, MK (1982). The target for initiation of delayed neurotoxicity by organophosphorus esters: Biochemical studies and toxicological applications. Rev. Biochem. Toxicol. 4: 141-212.

Johnson, MK (1990). Organophosphates and delayed neuropathy - is NTE alive and well? Toxicol. Appl. Pharmacol. 102(3): 385-399.

Kretzschmar, D; Hasan, G; Sharma, S; Heisenberg, M; Benzer, S (1997). The swiss cheese mutant causes glial hyperwrapping and brain degeneration in Drosophila. J. Neurosci. 17(19): 7425-7432.

Keynes, RD; Martins-Ferreira, H (1953). Membrane potentials in the electroplates of the electric eel. $J$. Physiol. 119(2-3): 315-51

Kolbezen, MJ; Metcalf, RL; Fukuto, TR (1954). Insecticidal activity of carbamate cholinesterase inhibitors. J. Agric. Food Chem. 2(17): 864-870.

Komloova, M; Musilek, K; Dolezal, M; Gunn-Moore, F; Kuca, K (2010). Structure-activity relationship of quaternary acetylcholinesterase inhibitors - outlook for early myasthenia gravis treatment. Curr Med Chem. 17(17): 1810-24.

Kuhr, RJ; Dorough, HW (1976). Carbamate Insecticide: Chemistry, Biochemistry, and Toxicology. Cleveland, Ohio. CRC Press: 189-220.

Loewenstein, Y; Gnatt, A; Neville, LF; Zakut, H; Soreq, H (1993) Structure-function relationship studies in human cholinesterases reveal genomic origins for individual variations in cholinergic drug responses.

Prog. Neuropsychopharmacol. Biol. Psychiatry.17(6):905-26

Lonsway, JA; Byers, ME; Dowla, HA; Panemangalore, M; Antonious, GF (1997). Dermal and respiratory exposure of mixers/sprayers to acephate, methamidophos, and endosulfan during tobacco production. Bull. Environ. Contam. Toxicol. 59(2): 179-186.

Lotti, M; Johnson, MK (1980). Repeated small doses of a neurotoxic organophosphate: monitoring of neurotoxic esterase in brain and spinal cord. Arch. Toxicol. 45(4): 263-271.

Lotti, M; Moretto, A (2006). Do carbamates cause polyneuropathy? Muscle. Nerve. 34(4): 499-502. 
Lush, MJ; Li, Y; Read, DJ; Willis, AC; Glynn, P (1998). Neuropathy target esterase and a homologous Drosophila neurodegeneration-associated mutant protein contain a novel domain conserved from bacteria to man. Biochem. J. 332(Pt 1): 1-4.

Lyaniwura, TT (1989). An in vitro evaluation of the potential toxicities and interactions of carbamate pesticides. Toxicol. in Vitro. 3(2): 91-93.

Main, AR (1964). Affinity and phosphorylation constants for the inhibition of esterases by organophosphates. Science 144: 992-993.

Main, AR (1980). Introduction to biochemical toxicology. Cholinesterase Inhibitor. Hodgson, ED \& Levis, FE. New York, Elsevier: 193-223.

Marrs, TC; Ballantyne, B (2004). Anticholinesterase insecticides. Pesticide Toxicology \& International Regulation. Marrs, TC \& Ballantyne, B. John Wiley \& Sons: 89-127.

Massoulié, J; Sussman, J; Bon, S; Silman, I (1993). Structure and functions of acetylcholinesterase and butyrylcholinesterase. Prog. Brain. Res. 98: 139-146.

Matsumura, F (1985). Metabolism of insecticides by animal and plants. Toxicology of Insecticides. Matsumura, F. New York \& London, Plenum Press: 203-289.

Metcalf, RL (1971). Structure-activity relationships for insecticidal carbamates. Bull. World. Health. Organ. 44(1-3): 43-78.

Metcalf, RL; Fukuto, TF; Collins, C; Borek, K; El-Aziz, SA (1968). Metabolism of 2,2-dimethyl-2,3dihydrobenzofuranyl-7 N-methylcarbamate (Furadan) in plants, insects, and mammals. J. Agr. Food Chem. 16(2): 300-311.

Moser, VC (1995). Comparisons of the acute effects of cholinesterase inhibitors using a neurobehavioral screening battery in rats. Neurotoxicol. Teratol. 17(6): 617-625.

Moser, VC (1999). Comparison of aldicarb and methamidophos neurotoxicity at different ages in the rat: behavioral and biochemical parameters. Toxicol. Appl. Pharmacol. 157(2): 94-106.

Moser, VC; McCormick, JP; Creason, JP; MacPhail, RC (1988). Comparison of chlordimeform and carbaryl using a functional observational battery. Fundam. Appl. Toxicol. 11(2): 189-206.

Mostafa, AA; Allam, KA (2001). Studies on the present status of insecticides resistance on mosquitoes using the diagnostic dosages in El-Fayium Governorate, a spot area of malaria in Egypt. J. Egypt. Soc. Parasitol. 31(1): 177-186.

Moretto, A; Lotti, M (2006). Peripheral nervous system effects and delayed neuropathy. Toxicology of Organophosphate \& Carbamate Compounds. Gupta, R. San Diego, California, Elsevier Academic Press: 361-370.

Mortensena, SR; Hooperb, MJ; Padillaa, S (1998). Rat brain acetylcholinesterase activity: developmental profile and maturational sensitivity to carbamate and organophosphorus inhibitors. Toxicology. 125(1): 13-19. 
N'Guessan, R; Darriet, F; Guillet, P; Carnevale, P; Traore-Lamizana, M; Corbel, V; Koffi, AA; Chandre, F (2003). Resistance to carbosulfan in Anopheles gambiae from Ivory Coast, based on reduced sensitivity of acetylcholinesterase. Med. Vet. Entomol. 17(1): 19-25.

Na-Bangchang, K; Congpuong, K (2007). Current malaria status and distribution of drug resistance in East and Southeast Asia with special focus to Thailand. Tohoku. J. Exp. Med. 211(2): 99-113.

Na-Bangchang, K; Karbwang, J (2009). Current status of malaria chemotherapy and the role of pharmacology in antimalarial drug research and development. Fundam. Clin. Pharmacol. 23(4): 387-409.

Nation, JL (2002). Neurophysiology. Insect Physiology and Biochemistry. Nation, JL. CRC Press: 229265.

O'Brien, RD (1967). Insecticides: Action and Metabolism. New York, Academic Press: 32-70.

O'Meara, WP; Mangeni, JN; Steketee,R; Greenwood, B (2010). Changes in the burden of malaria in subSaharan Africa. Lancet. Infect. Dis. 10(8): 545-555.

Oonnithan, ES; Casida, JE (1968). Oxidation of methyl and dimethylcarbamate insecticide chemicals by microsomal enzymes and anticholinesterase activity of the metabolites. J. Agr. Food. Chem. 16(1): 28-44.

Ordentlich, A; Barak, D; Kronman, C; Ariel, N; Segall, Y; Velan, B; Shafferman, A (1998). Functional characteristics of the oxyanion hole in human acetylcholinesterase. J. Biol. Chem. 273(31): 19509-19501.

PAN Pesticides Database (2000). Toxicity studies for bendiocarb on fish. Chemical Toxicity Studies on Aquatic Organisms. From

http://www.pesticideinfo.org/List_AquireAll.jsp?Rec_Id=PC32991\&Taxa_Group=Fish.

PAN Pesticides Database (2000b) Toxicity of Bendiocarb. From

http://pesticideinfo.org/Summary_Chemical.jsp?Rec_Id=PC32991

PAN Pesticides Database (2005). Bendiocarb. Pesticides News 68: 20-21. From http://www.panuk.org/pestnews/Actives/Bendiocarb.htm

Parke, DV; Williams, RT (1969). Metabolism of toxic substances. Br. Med. Bull. 25(3): 256-262.

Parkin, J; Shea, C; Sant, GR (1997). Intravesical dimethyl sulfoxide (DMSO) for interstitial cystitis - a practical approach. Urology. 49(5A): 105-107.

Parkinson, A (2001). Biotransformation of xenobiotics. Casarett \& Doull's Toxicology. Klaassen, C. New York, McGraw-Hill: 133-224.

Parvez, H; Parvez, SH; Reiss, C; Labbe, G (2001). Molecular Responses to Xenobiotics. Parvez, H \& Reiss, C. Elsevier Science Ltd:: 293-312.

Pavlic, MR (1975). The influence of some acetylcholine-receptor activating and blocking agents on the esteratic site of acetylcholinesterase. Biochem. Pharmacol. 24(21): 2000-2002.

Pekas, JC; Paulson, GD (1970). Intestinal hydrolysis and conjugation of a pesticidal carbamate in vitro. Science 170(3953): 77-78. 
Pelekis, M; Krishnan, K (1997). Determination of the rate of aldicarb sulphoxidation in rat liver, kidney and lung microsomes. Xenobiotica. 27(11): 1113-1120.

Popov, AF; Nikiforov, ND; Sergiev, VP; Sanin, BI (2003). Modern treatment of malaria. Klin. Med. (Mosk). 81(7): 15-19.

Proudfoot, A (2006). The early toxicology of physostigmine: a tale of beans, great men and egos. Toxicol. Rev. 25(2): 99-138.

Quinn, DM (1987). Acetylcholinesterase: enzyme structure, reaction dynamics, and virtual transition states. Chem. Rev. 87(5): 955-979.

Radic, Z; Taylor, P (2006). Structure and function of cholinesterases. Toxicology of Organophosphate \& Carbamate Compounds. Gupta, R. San Diego, California, Elsevier Academic Press: 161-186.

Randall, JC; Ambroso, JL; Groutas, WC; Brubaker, MJ; Richardson, RJ (1997). Inhibition of neurotoxic esterase in vitro by novel carbamates. Toxicol. Appl. Pharmacol. 143(1): 173-178.

Rathmann, KL; Conner, CS (2007). Alzheimer's disease: clinical features, pathogenesis, and treatment. Ann. Pharmacother. 41(9):1499-504.

Reiner, E; Skrinjaric-Spolhar, M; Sinko, G; Simen-Rudlf, V (2000). Comparison of protocols for measuring of human blood cholinesterases by the Ellman Method. Arh. Hig. Rada. Toksikol. 51(1): 13-18.

Richardson, RJ (1992). Interactions of organophosphorus compounds with neurotoxic esterase. Organophosphates. Chambers, JE \& Levis, PE. San Diego. California, Academic Press, Inc.: 299-323.

Ringwald, P (2001). Resistant malaria in children. Indian Pediatr. 38(1): 9-14.

Ringwald, P (2007). Current antimalarial drugs: resistance and new strategies. Bull. Acad. Natl. Med. 191(7): 1273-1284.

Brodie, BB; Gillette , JR, Ladu, BN (1958). Enzymatic metabolism of drugs and other foreign compounds. Annu. Rev. Biochem. 27(3): 427-454.

Rosman, Y; Makarovsky, I; Bentur, Y; Shrot, S; Dushnistky, T; Krivoy, A (2009). Carbamate poisoning: treatment recommendations in the setting of a mass casualties event. Am. J. Emerg. Med. 27(9).11171124.

Salisbury, BG; Tate, CF Jr; Davies, JE. (1974). Baygon-induced pulmonary edema. Chest. 65(4): 455-457.

Santos, NC; Figueira-Coelho, J; Martins-Silva, J; Saldanha, C (2003). Multidisciplinary utilization of dimethyl sulfoxide: pharmacological, cellular, and molecular aspects. Biochem. Pharmacol. 65(7): 10351041.

Santos, NC; Prieto, MJE; Morna-Gomes, A; Betbeder, D; Castanho, MARB (1997). Structural characterization (shape and dimensions) and stability of polysaccharide/lipid nanoparticles. Biopolymers. 41(5): 511-520.

Sassard, J; Bernard, N; Legheand, J; Cuisinaud, G; Traeger, J (1979). Pharmacokinetics and bioavailability of pyridinol carbamate in humans. J. Pharm. Sci. 68(9):1190-1. 
Schmidt-Nielsen, K (1997). Chapter 13: Information and Senses. Animal Physiology: Adaptation and Environment. Schmidt-Nielsen, K. Cambridge University Press. 529-579.

Schlagenhauf, P; Petersen, E (2009). Antimalaria drug resistance: the mono-combi-counterfeit triangle. Expert. Rev. Anti. infect. Ther. 7(9): 1039-1042.

Schlitzer, M (2008). Antimalarial drugs - what is in use and what is in the pipeline? Arch. Pharm. (Weinheim) 341(3): 149-163.

Segel, IH (1975). Enzyme Kinetics. New York, John Wiley \& Sons: 506-845.

Shafferman, A; Ordentlich, A; Barak, D; Stein, D; Ariel, N; Velan, B (1996). Aging of phosphylated human acetylcholinesterase: catalytic processes mediated by aromatic and polar residues of the active center. Biochem. J. 318(Pt 3): 833-840.

Sies, H; Packer, L (2005). Phase II conjugation enzymes and transport systems. San Diego, California, Elsevier Academic Press.

Smith, MI; Elvove, E; Frazier, WH (1930). The pharmacological action of certain phenol esters, with special reference to the etiology of so-called ginger paralysis. Public. Health. Rep. 45: 2509-2524.

Stumpf, AM; Tanaka, D Jr; Aulerich, RJ; Bursian, SJ (1989). Delayed neurotoxic effects of tri-o-toyl phosphate in the European ferret. J. Toxicol. Environ. Health. 26(1): 61-73.

Sultatos, LG (2006). Interactions of organophosphorus and carbamate compounds with cholinesterases. Toxicology of Organophosphate \& Carbamate Compounds. Gupta, R. San Diego, California, Elsevier Academic Press: 209-218.

Sussman, JL; Harel, M; Frolow, F; Oefner, C; Goldman, A; Toker, L; Silman, I (1991). Atomic structure of acetylcholinesterase from Torpedo californica: a prototypic acetylcholine-binding protein. Science 253(5022): 872-879.

Swale, RD (2009). Determination of allosteric solvent effects between acetylcholinesterase and mosquito selective carbamates: implications for high throughput screening of insecticides. Entomology. Blacksburg, Virginia Polytechnic Institute and State University. Master of Science.

Tang, J; Rose, RL; Chambers, JE (2006). Metabolism of organophosphorus and carbamate pesticides. Toxicology of Organophosphate \& Carbamate Compounds. Gupta, R. San Diego, California, Elsevier Academic Press: 127-143.

Taylor, P; Radic, Z (1994). The cholinesterases: from genes to proteins. Annu. Rev. Pharmacol. Toxicol. 34: 281-320.

Tetteh, KK; Polley, SD (2007). Progress and challenges towards the development of malaria vaccines. BioDrugs. 21(6): 357-373.

Thompson, CM; Richardon, RJ (2004). Anticholinesterase insecticides. Pesticide Toxicology. Marrs, TC \& Ballantyne, B. London, UK. John Wiley \& sons, Ltd: 90-127. 
Timchalk, C (2006). Physiologically based pharmacokinetic modeling of organophosphorus and carbamate pesticides. Toxicology of Organophosphate \& Carbamate Compounds. Gupta, R. San Diego, California, Elsevier Academic Press: 103-125.

Tjernberg, A; Markova, N; Griffiths, WJ; Hallen, D (2006). DMSO related effects in protein characterization. J. Biomol. Screen. 11(2): 131-137.

Ulvestad, A; Gerner, T (1984). Effects of alpha- and beta-adrenergic agents and dopamine on gastric motor activity stimulated by acetylcholine or physostigmine. Scand. J. Gastroenterol. Suppl. 89:59-63

Van den Berg, H (2009). Global status of DDT and its alternatives for use in vector control to prevent disease. Environ. Health. Perspect. 117(11): 1656-1663.

Veronesi, B (1984). A rodent model of organophosphorus-induced delayed neuropathy: distribution of central (spinal cord) and peripheral nerve damage. Neuropathol. Appl. Neurobiol. 10(5): 357-368.

Versteeg, DJ; Stalmansb, M; Dyera, SD; Janssen, C (1997). Ceriodaphnia and daphnia: a comparison of their sensitivity to xenobiotics and utility as a test species. Chemosphere. 34(4): 869-892

Viragh, C; Akhmetshin, R; Kovach, IM; Broomfield, C (1997). Unique push-pull mechanism of dealkylation in soman-inhibited cholinesterases. Biochemistry. 36(27): 8243-8352.

WHO (1986). Carbamate pesticides: a general introduction Enviormental Health Criteria. From http://www.inchem.org/documents/ehc/ehc/ehc64.htm\#SubSectionNumber:6.2.3.

WHO (2005). State of the art of new vaccines: research and development. From http://www.who.int/vaccine_research/documents/stateoftheart/en/index.html

Wiesner, J; Kriz, Z; Kuca, K; Jun, D; Koca, J (2007). Acetylcholinesterase - the structural similarities and differences. J. Enzyme. Inhib. Med. Chem. 22(4): 417-424.

Williams, DG (1983). Intramolecular group transfer is a characteristic of neurotoxic esterase and is independent of the tissue source of the enzyme. Biochem. J. 209(3): 817-829.

Williams, RT (1959). Detoxification mechanisms: the metabolism and detoxification of drugs, toxic substance, and other organic compounds. New York, NY, John Wiley \& Sons: 46-69.

Wilson, IB; Hatch, MA; Ginsburg, S (1960). Carbamylation of acetylcholinesterase. J. Biol. Chem. 235: 2312-2315.

Wilson, IB (1951). Mechanism of enzymic hydrolysis. I. Role of the acidic group in the esteratic site of acetylcholinesterase. Biochim. Biophys. Acta. 7(3): 466-470.

Wilson, IB; Ginsburg, B (1955). A powerful reactivator of alkyphosphate inhibited acetylcholinesterase. Biochim. Biophys. Acta. 18(1): 168-170.

Wilson, IB; Ginsburg, S; Quan, C (1958). Molecular complementariness as basis for reactivation of alkyl phosphate-inhibited enzyme. Arch. Biochem. Biophys 77(2): 286-296.

Wright, CG; Leidy, RB.; Dupree, HE (1981). Insecticides in the ambient air of rooms following their application for control of pests. Bull. Environ. Contam. Toxicol. 26(4): 548-543. 
Yamada, M; Marui, Y; Hayashi, C; Miki, Y; Takemura, S (2001). New thiocholine ester substrates for the assay of human serum cholinesterase. Clin. Chem. 47(11): 1962-1966. 